\title{
HOW ACCURATELY DOES 70\% FINAL EMPLOYMENT EARNINGS REPLACEMENT MEASURE RETIREMENT INCOME (IN)ADEQUACY? INTRODUCING THE LIVING STANDARDS REPLACEMENT RATE (LSRR)
}

BY

\author{
Bonnie-JeAnne MacDonald, LARs Osberg And Kevin D. Moore
}

\begin{abstract}
Will 70\% of a worker's final annual employment earnings sustain living standards after retirement? Despite increasing skepticism, the most dominant measure of retirement income adequacy by financial planners, pensions plan advisors, academics and public policy makers is the "final employment earnings replacement rate", where $70 \%$ is considered the right target to ensure living standards remain at approximately the same level after retirement. Using Statistics Canada's LifePaths dynamic population micro-simulation model, this paper asks whether those individuals from the 1951-1958 Canadian birth cohort who attain roughly a 70\% final employment earnings replacement rate (as conventionally measured) at retirement do, in fact, achieve approximate continuity in their living standards. We find that the conventional final earnings replacement rate measure has little predictive value for living standards continuity between working-life and retirement. The primary reason is that employment earnings in a single year is not a reliable representation of a worker's standard of living it relies on an inadequate pre-retirement measurement period, does not incorporate important components of consumption sources (such as home equity), and ignores household size (particularly children). As a result, we find that the correlation between the conventional earnings replacement rate and actual living standards continuity is relatively low (0.11). The paper therefore suggests an alternative metric for assessing how well a worker's living standard is maintained after retirement - i.e., the Living Standards Replacement Rate, or the LSRR. The LSRR provides a more accurate, understandable and consistent measure of retirement income adequacy.
\end{abstract}

\section{KEYWORDS}

Retirement income adequacy, 70\% earnings replacement rate, micro-simulation, standard of living, Living Standards Replacement Rate, LSRR, retirement planning, employer pension plan design, public pension plan design 


\section{INTRODUCTION}

The capacity of retirement income to sustain the standard of living of future seniors is a growing concern in Canada and elsewhere, owing to (1) low interest rates, (2) high investment fees, (3) longer life expectancies, (4) rising divorce rates among seniors (with likely negative financial implications), (5) an aging population, (6) an increasing reliance on paid services for the potentially costly expenses associated with chronic health conditions and (7) less secure sources of retirement income. ${ }^{1}$ For example, the shift among employer pension plans from defined benefit (DB) to defined contribution (DC) in many countries around the world largely shifts the market risk of benefit payments to individual retirees.

A common response to these concerns is to encourage individuals to save more. But saving too much for retirement has its disadvantages. Very high levels of saving could be a rational strategy for highly risk-averse individuals who place a high value on contingency income, for individuals anticipating higher expenses after retirement (such as home repairs and covering medical expenses not covered by the state health care system), and for individuals wishing to leave bequests or improve their living standards in retirement. For others, however, over-saving could mean unnecessary "scrimping and saving" during young and healthy years when the welfare of children is possibly involved, and could produce excess wealth that is not necessarily enjoyed much, at the margin, during more advanced ages. For instance, Smith et al. (2009) found that retirees consume their personal savings at a very slow rate (the personal wealth of the upper income quintile actually continued to accumulate after retirement).

The most widespread metric for evaluating the adequacy of retirement savings has historically been the "final earnings replacement rate", where $70 \%$ has been advocated as the right target. Financial planners widely use the earnings replacement rate benchmark, as do pension plan advisors, academics and public policy makers. It also underlies much of the research that has predicted that a large proportion of Canadian and American workers will be financially unprepared for an adequate retirement. In Canada, for example, workers have often been told to aim for a $70 \%$ replacement rate of final employment earnings in order to maintain their working-life standard of living after retirement. The Baldwin Report (2009: iv) stated, "The common approach to determining whether the elderly are maintaining their standard of living is to compare the income of the elderly population with their pre-retirement earnings. This comparison is called the replacement rate and it is usually expressed as a percentage. Actual replacement rates are compared with a benchmark replacement rate - usually in the range of 70 to 75 per cent of gross pre-retirement earnings - to decide whether people are maintaining their pre-retirement standard of living". Liu et al. (2013: 8) similarly wrote: "One approach taken in the literature is to assess the adequacy of retirement income by focusing on the proportion of pre-retirement income that has to be replaced during retirement in order to maintain living standards at the pre-retirement level. A rule of thumb is that post-retirement income should replace at least $70 \%$ of pre-retirement income". The same 
target measure is conventionally advocated in other countries - for example, the U.S. Social Security Administration (2008:7) wrote: "(w)hile Social Security replaces about 40 percent of the average worker's pre-retirement earnings, most financial advisors say that you will need 70 percent or more of pre-retirement earnings to live comfortably". Moreover, the assumption that $70 \%$ final earnings replacement after 35 years of service is the appropriate retirement income target underlies the design of most employer DB pension plans. At the individual level, it is currently the "staple of web-based financial planning products" (Scholz and Seshadri, 2009).

Studies skeptical about whether target earnings replacement rates provide an adequate benchmark for assessing the adequacy of an individual's retirement income include Vanderhei (2006) and Scholz and Seshadri (2009). This paper continues that tradition by testing the earnings replacement rate measure empirically - asking how well living standards are maintained by simulated individuals who actually achieve the often-advocated $70 \%$ target. The paper then goes on to suggest a more accurate metric of retirement income adequacy.

We examine Canadians who attain approximately a $70 \%$ final employment earnings replacement target at retirement, and ask how well each such person's working-life living standard is maintained after retirement. More specifically, for individuals projected to retire at age 61 (the median retirement age in Canada $^{2}$ ) between years 2012 and 2019, we calculate the final employment earnings replacement rate for each person and select those for whom the final earnings replacement rate lies between $65 \%$ and $75 \%$. For each such individual, we then compare average post-retirement living standards to average preretirement living standards, to evaluate whether there is, in fact, approximate continuity in his/her living standards.

To estimate living standards over the life course, we utilize Statistics Canada's LifePaths dynamic micro-simulation model of the Canadian population, ${ }^{3}$ which provides the level of detail necessary for evaluation of living standards before and after retirement. LifePaths is a long-standing model whose development began in the early 1990s. Although models like LifePaths can never be perfect substitutes for actual data, large-scale, complex, dynamic microsimulation models are increasingly becoming the international tool of choice for assessing retirement income adequacy, as well as a variety of other analyses.

In addition to testing the accuracy of the conventional earnings replacement rate measure and the $70 \%$ target, this paper presents a framework for a statistic that more accurately assesses how well a worker's living standards are maintained after retirement using income and wealth data - the Living Standards Replacement Rate (LSRR). The goal of the LSRR is to capture a worker's living standards continuity after retirement, by comparing how much money a worker has available to support personal consumption of goods and services before and after retirement. Its purpose is to serve as a retirement income adequacy statistic that is more accurate, understandable and consistent in its application to analysis compared to the conventional earnings replacement rate measure. We hope that the LSRR can provide a better metric for public policy analysts, pension 
plan advisors, financial analysts and academics when measuring retirement income adequacy.

Section 2 of this paper reviews the conventional final employment earnings replacement rate measure; Section 3 presents the LSRR and outlines our methods; Section 4 analyzes our results; Section 5 discusses future work in terms of practical considerations when adopting the LSRR; and Section 6 concludes.

\section{RePlacement RAtes AND RePlacement RAte TARgets - REVIEW AND DISCUSSION}

The common criterion for retirement income adequacy is whether working-life living standards are sustained after retirement and the conventional statistic for evaluating an individual's likely living standards in retirement relative to working life is the final employment earnings "replacement rate" - i.e., the fraction of a worker's annual final employment earnings replaced by annual retirement income. Across academia, industry, and government public policy research, the earnings replacement rate is the most prevalent statistic for measuring retirement income adequacy, and many analyses rely on it exclusively. ${ }^{4}$

The apparent simplicity of the earnings replacement rate approach has been a primary reason for its popularity. There exist, however, major inconsistencies in the analysis of earnings replacement rates owing to differences in the conceptual framing of retirement income adequacy ${ }^{5}$ as well as analytical purpose, ${ }^{6}$ but most of all owing to data constraints.

From the perspectives of the policy analyst, academic, financial planner, employer and the individuals themselves, the most easily obtainable data is currentyear before-tax earnings data. For example, current year earnings are commonly collected in public surveys; a client who visits his/her financial planner typically brings his/her most recent income tax return; and employers who sponsor a pension plan have the current year payroll for their employees. Having this limited data readily at hand, retirement income adequacy has historically been measured using the "final employment earnings replacement rate", which is conventionally calculated as

$$
\begin{aligned}
& \text { Conventional final employment earnings replacement rate } \\
& =\frac{\text { gross (i.e., before-tax) income in first year of retirement }}{\text { gross pre-retirement final year employment earnings }} .
\end{aligned}
$$

The conventional final employment earnings replacement rate is sometimes also referred to as the "gross" employment earnings replacement rate since it is calculated using pre-tax employment earnings and pre-tax retirement income. The "retirement income" in the conventional earnings replacement rate formula consists of income reported for income tax purposes (and therefore routinely does not include savings whose withdrawals are not taxed). (Note that Equation (1) is intended to represent the most conventional earnings replacement 
rate formula, although the authors were unable to locate an original source that prescribes this measure.)

The "rule-of-thumb" belief is that $70 \%$ final employment earnings replacement will sustain a worker's standard of living after retirement - i.e., provide $100 \%$ replacement of pre-retirement living standards. This expectation is based on the idea that retired individuals will generally pay lower taxes, not be saving for retirement, typically have paid off their mortgage and no longer need to support children and/or pay work-related expenses. It also stems from the perspective that, since retirement is the end of employment, only employment earnings should be replaced.

Unfortunately, many components of living standards are either poorly dealt with, or omitted from, Equation (1):

1. household-level differences in individual consumption due to family size, particularly dependent children (and changes over time in household size and composition);

2. the return on house ownership, or "imputed rent";

3. taxes (specifically the differentials in taxation year-by-year, pre- and postretirement);

4. government transfers (e.g., unemployment insurance, child benefits and social assistance);

5. the accumulation and drawdown of non-traditional forms of savings (e.g., non-tax-sheltered financial wealth, debt, and home-ownership equity);

6. earnings volatility (discussed more below);

7. retirement income volatility;

8. pre- and post-retirement risks (e.g., poor financial market returns, death/divorce of a spouse, longevity, expensive medical conditions, extended care needs and inflation uncertainty);

9. phased retirement and continuing employment income after retirement;

10. individual preferences (e.g., risk aversion, the value of leisure and bequest motives);

11. changes in expenses over the life course.

By way of example, consider \#6 (the omission of earnings volatility). When calculating the denominator of Equation (1), the choice between using earnings in the final year of employment (such as age 64) versus a longer measurement period (such as averaged from age 60-64) can produce substantial discrepancies across the results, due to short- and long-term earnings volatility across workers' careers (see Finnie, 1999; Morissette et al., 2007; Finnie and Gray, 2011). Biggs and Springstead (2008), Munnell and Soto (2005) and Boskin and Shoven (1987) are examples of studies that observed an enormous impact of the measurement period choice on the resulting replacement rate, leading to quite different conclusions about replacement adequacy.

Owing to these omissions, some literature has questioned the validity of target earnings replacement rates as a benchmark for assessing retirement income adequacy. Engen et al. (1999) pointed out that the existence of risk necessarily 
creates a distribution of target earnings replacement rates whose mean or median can only be interpreted as such, and not as a minimum single target. In more recent literature, using longitudinal data from the Health and Retirement Study and a life-cycle consumption and savings model, Scholz and Seshadri (2009) found that optimal gross earnings replacement rates covered a very wide range - concluding, "What is clear from this discussion is that the substantial variation in optimal target replacement rates presents a challenge for developing sensible replacement rate rules of thumb. Conventional advice may overstate optimal targets by a factor of two, or understate retirement consumption needs by a factor of three depending on the idiosyncratic experiences of households" (21). VanDerhei (2006) also found that "a simple one-size-fits-all replacement rate will not work for most Americans" (5). Simulating 1,000 lifepaths of stylized 65-year-old retirees and testing the adequacy of earnings replacement rate targets, he concluded that "the huge variation in the range of replacement rate targets - depending on the individual's income, degree of annuitization for initial retirement wealth, and the asset allocation of the postretirement investments - call into question whether the use of a single rule-ofthumb measure is realistic to use in the retirement planning process" (5).

Owing to the generally understood gap between the objective of the earnings replacement rate benchmark (that is, to measure the continuity of a worker's living standards after retirement) and its limited formulation (being simply the ratio of gross retirement income divided by gross final employment earnings), analysts seeking to improve on its methodological weaknesses have applied it in a wide variety of ways. The refinements made by analysts are often driven by data availability. Consequently, the replacement rate calculation has been very inconsistent across analyses, which has led to varying and often conflicting results regarding retirement income adequacy (as we discuss further in Sections 4 and 5). Appendix $C$ discusses the methodological weaknesses listed above, and provides examples of the varied approaches taken in literature.

\section{CONCEPTUAL AND METHOdOlOGiCAl FRAMEWORK FOR RETIREMENT INCOME ADEQUACY}

\subsection{Why Microsimulation?}

As discussed in Section 2, analysts often tweak the earnings replacement rate measure by incorporating some improvements to the conventional formula, and the availability of data often shapes these improvements. This is particularly true in analyses at the population-level. For example, available longitudinal population data rarely reports on all components of income, savings, dissavings and wealth, making it difficult for analysts to investigate the adequacy of a country's pension system for future retirees. Although more comprehensive data can sometimes be found in cross-sectional surveys reporting on a particular year, having only a single year of data often constrains analysts to projections using 
highly stylized assumptions that do not capture the realistic variability across and among the life courses of individuals within a population. Examples include Palmer (1988), Mitchell and Moore (1998), Munnell et al. (2006) and Palmer (2008). In comparison, replacement rate studies that employed longitudinal data include Boskin and Shoven (1987), Smith (2003), Munnell and Soto (2005), LaRochelle-Cote et al. (2008), Ostrovsky and Schellenberg (2009) and Denton et al. (2011).

As a result, large-scale, complex, dynamic micro-simulation models are increasingly being used to assess retirement income adequacy, because they have the potential to

- integrate and extend existing data sources to give the most comprehensive picture of consumption sources before and after retirement;

- model individuals' interactions with and accruals under retirement income programs throughout their entire lifetime, simultaneously enabling full flexibility in analysis;

- generate results that reflect the realistic complexity and diversity within lifecourses, and across individuals;

- model the likely impact of current socio-economic trends on future outcomes, and facilitate explicit evaluations of the uncertainty of the future (including the post-retirement risks that people face).

For example, micro-simulation enables nearly full flexibility to choose alternative measurement periods before and after retirement rather than depend exclusively on employment earnings in the year before retirement (as noted earlier, the measurement period choice plays a critical role in the results of replacement rate analyses). For example, using the U.S. Social Security Administration's Modeling Income in the Near Term (MINT) micro-simulation model, Butrica et al. (2003) measured and averaged pre-retirement income from ages 22 to 62. Also using the MINT micro-simulation model, Biggs and Springstead (2008) compared the different results that follow from using various measurement periods for earnings, including a variety of career-average and final average earnings measures.

As Klevmarken explained nearly two decades ago "The micro-simulation approach is thus primarily designed for studies of the distributional effects of economic policy, and one of its main advantages is that it permits assumptions of heterogeneous behavior" (Klevmarken 1997: 2). In other words, it allows people to act differently, rather than assume that everyone behaves like the "average". "This, as a matter of fact, widens the scope of micro-simulation beyond that of conventional econometric modeling. When economic relations are highly nonlinear, when tax laws and rules of transfer programs introduce censoring and truncation and when sub-populations differ in behavior, then models of average behavior become inadequate to evaluate the average impact of policy changes, while a micro-simulation model can be used also for this purpose" (ibid). Owing to their advantages, dynamic micro-simulation models are ever more the tool of choice by policy makers throughout the industrialized world for analysis 
relating to the ageing of the population and future retirement income system outcomes - in addition to Statistics Canada's LifePaths, examples include APPSIM in Australia (Harding, 2007), CBOLT in the United States (O'Harra et al., 2004) and MIDAS in Belgium (Dekkers and Belloni, 2009). Interested readers are directed to Li and O'Donoghue (2013) for a recent survey of dynamic micro-simulation models internationally, including their uses, model structure and methodology. ESPlanner (Bernheim et al., 2000; Kotlikoff, 2006) in the United States and Ruthen (Avery and Morrison, 2009) in Canada are examples of personal dynamic micro-simulation models for individual financial planning purposes.

\subsection{Tool of analysis: LifePaths}

To benefit from the advantages of dynamic micro-simulation modeling identified in Section 3.1, the present paper evaluates living standards continuity by building on Statistics Canada's LifePaths micro-simulation model (Spielauer, 2013).

LifePaths is a dynamic micro-simulation model of the Canadian population that simulates individual life-courses (birth, education, employment, income, taxes, marriage, child-bearing, retirement, etc) of synthetic individuals that are representative of the Canadian population. Using behavioral equations, it simulates each "life-path" year-by-year and case-by-case, while striving to incorporate the diversity between individuals and over each person's lifecourse. LifePaths summarizes, incorporates and integrates an enormous range of Canadian data in order to simulate statistically representative data samples of the history of the Canadian population. Examples of studies that employed LifePaths in the context of projecting the retirement income adequacy of Canadians include Moore et al. (2010), MacDonald et al. (2011) and Wolfson (2011). Appendix D provides a further description of LifePaths.

Using LifePaths' simulations, we compute estimates for individual living standards across the life-course to evaluate how well living standards are maintained by people who approximately hit a $70 \%$ earnings replacement rate target. We use a comprehensive definition of income that includes nontraditional working and retirement income sources, and we go beyond the single year before and after retirement to look over the individual's entire lifetime (year-by-year at the family level, making appropriate adjustments for family size). We stochastically model financial market returns and mortality (including the death of family members). Individuals exit the workforce in a realistic manner that matches Canadian labor force data.

\subsection{Living Standards Replacement Rate (LSRR)}

This section suggests a metric that more comprehensively and accurately determines how well a person's working-life living standards are replaced in 
retirement - the LSRR. The goal of the LSRR is to capture a worker's living standards continuity after retirement, by calculating how much money a worker has available to support his/her personal consumption of goods and services before and after retirement.

(After presenting the LSRR in this section, we next use the LSRR in Section 4 to measure the continuity of living standards for workers who attain a $65 \%$ $75 \%$ conventional earnings replacement rate. Section 5 discusses the value of adopting the LSRR as a retirement income adequacy statistic, as well as some practical considerations when doing so.)

The LSRR measures living standards by calculating the flow of income available to support the individual's standard of living pre- and post-retirement (in other words, the income available to support the consumption of goods and services). During the working-years, the LSRR assumes that the income available for individual consumption equals his/her family's disposable income (gross income after taxes and transfers) less net savings, and then adjusted for family size. During retirement, it assumes that the income available for individual consumption would equal disposable income plus the drawdown from accumulated savings, which would also be calculated at the family level and adjusted for family size. In short, the LSRR captures living standards by determining the amount of money that the individual has available to spend before and after retirement to support his/her personal level of consumption.

Figure 1 presents the LSRR framework for estimating an individual's living standards each year while working, and his/her potential living standards in retirement.

Once an individual's living standards are estimated for each year of life, then the LSRR is simply the average estimated retirement living standards divided by the average estimated working-life living standards. More precisely, with an accounting period of one fiscal year, the LSRR is calculated as

$$
\begin{aligned}
& \text { Living Standards Replacement Rate (LSRR) } \\
& =\frac{\text { average annual retirement living standards }}{\text { average annual working-life living standards }} \\
& =\frac{\text { average real annual retirement income for potential individual consumption expenditure }}{\text { trimmed average real annual working income for individual consumption expenditure }} .
\end{aligned}
$$

"Real" or "constant dollar" income is calculated using the All-Items Consumer Price Index for Canada. We use a trimmed average of income in the working life: Using the 30 years leading up to retirement, we remove the incomes in the lowest and highest five years, and average the real income of the remaining middle 20 years. We chose to trim our average, as trimming reduces the influence of outlier years - e.g., both abnormally low (possibly negative) and unusually high employment earning years - which is particularly important 


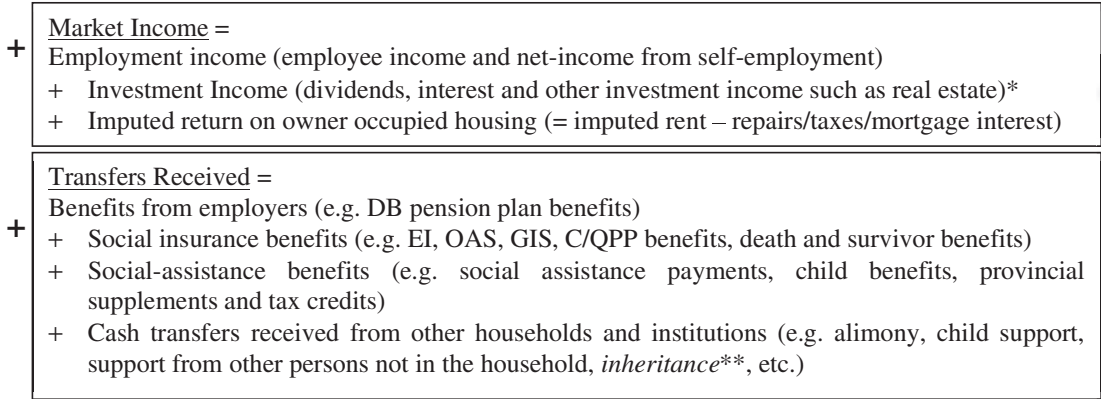

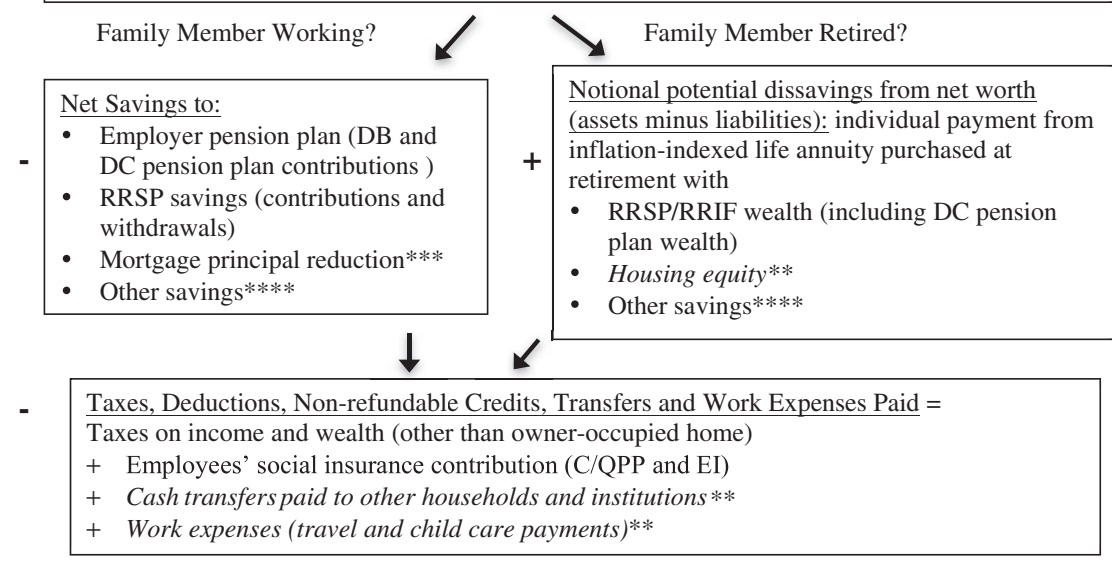

$=$ Cumulative Income for Family Consumption Expenditure

Repeat for each family member

$\div \quad$ LIS equivalence scale $=(\text { Number of Family Members })^{0.5}$

Subject Individual Working? $\downarrow$
$=$\begin{tabular}{|l|l|}
\hline $\begin{array}{l}\text { Annual Working Income for Individual } \\
\text { Consumption Expenditure (proxy for fiscal } \\
\text { year's Working Life Living Standards) }\end{array}$ & $\begin{array}{l}\text { Annual Retirement Income for Potential } \\
\text { Individual Consumption Expenditure (proxy } \\
\text { for fiscal year's Retirement Living Standards) }\end{array}$ \\
\hline
\end{tabular}

FIGURE 1: LSRR's conceptual framework to measure an individual's fiscal year's "living standards" (using census family-level data of subject individual).

Notes: * If any portion of investment income is saved rather than consumed, that portion would then be added to savings and hence subtracted (having zero net effect, aside from any possible tax implications). ${ }^{* *}$ The italicized items are those not included in this paper. We do not model work expenses and we assume that seniors do not draw down their housing equity to support consumption. We do not explicitly model the receipt of inheritance, although past inheritances are recorded in wealth and therefore are implicitly treated as past savings. LifePaths does not model cash transfers paid to other households, although it does loosely model

cash transfers received. ${ }^{* * *}$ Retiring homeowners with a mortgage may also continue to make principal payments into retirement depending of the analyst's treatment of housing equity. For instance, this paper does not assume that the retiree downsizes at retirement by selling his/her home, and therefore he/she continues to benefit from imputed rent and may make mortgage payments. Note that the interest portion of mortgage payments is incorporated as a component of the imputed return on owner occupied housing. **** The "other savings" concept used is marketable wealth (or net worth) other than primary housing. These include the sum of non-registered financial assets (chequing accounts, GICs, trusts, etc), real estate assets (other than primary

housing), and business equity, less non-mortgage debt (credit card, lines of credit, car loans, etc).

Acronyms in Figure 1: The Canadian public pension system consists of the universal Old Age Security program (OAS), the income-tested Guaranteed Income Supplement program (GIS) and the earnings-based contributory state plan - the Canadian/Quebec Pension Plans (C/QPP). Registered Retirement Savings Plans

(RRSPs) and Registered Retirement Income Funds (RRIFs) are tax-sheltered retirement savings.

Employment Insurance (EI) provides temporary financial aid to Canadians who have lost their jobs. 
among the self-employed. Note that the results were not largely impacted had we used a conventional average (for $92 \%$ of the sample, the trimmed average lies between $90 \%$ and $110 \%$ of the full 30 -year average). Regardless of the method of averaging, it is crucial to use a representative number of years in the calculation (so as to smooth out year-to-year volatility). (Section 5 discusses this further).

Our estimate for annual retirement living standards (the annual "Retirement Income for Potential Individual Consumption Expenditure" in Figure 1) is averaged from retirement until death. We do not trim the average since the stability of retirement income sources is particularly high relative to employment earnings volatility (see Finnie, 1999; Morissette et al., 2007; Finnie and Gray, 2011), especially given that we assume the full annuitization of savings (as we discuss below).

Since our focus is retirement income adequacy, we infer what individuals could potentially consume in retirement. As is customary in this literature, we convert the stock of wealth into a flow of potential annual consumption by assuming that wealth (net worth $=$ assets - liabilities) is annuitized at retirement. This is a simplifying assumption, although not a realistic one - we discuss the issues surrounding this assumption at the end of this section. The payments of this notional annuity are added to other retirement income flows. The "potential dissavings from net worth" portion in Figure 1 is, therefore, the annual potential payout from an inflation-indexed life annuity purchased at retirement with: registered and non-registered wealth, ${ }^{7}$ real estate investments, and business equity, minus debt. To compute individual equivalent income, we measure income flows at the census-family level, correct for inflation, and adjust for family size using the Luxembourg Income Study (LIS) equivalence scale (the square root of household size ${ }^{8}$ ).

For our analysis in Section 4, we use $80 \%<$ LSRR $<120 \%$ as the range of outcomes compatible with living standards continuity (i.e., working life "living standards" plus or minus 20\%). Although these ranges are subjective, some support can be drawn from Binswanger and Schunk (2012: 217), which found that, "a large majority of individuals aims to achieve a spending profile where, under normal circumstances, old-age spending exceeds 80 percent of workinglife spending" using individually tailored internet surveys in the United States and the Netherlands. ${ }^{9}$

The differences between the conventional earnings replacement rate from Equation (1) and the LSRR from Equation (2) are as follows: (1) The LSRR uses a much broader measurement period for pre- and post-retirement, (2) the LSRR measures income at the family level rather than at the level of the individual and (3) the LSRR includes a much more comprehensive definition of income. To illustrate, we next consider these differences in turn between Equation (1) and Equation (2) (assuming a retirement age of 61). Note that these formulas use an accounting period of a full fiscal year (not included are the partial year of death as well as the first year of retirement, when the subject is working a part of the year and retired the other part). 
Conventional replacement rate from Equation (1)

$=\frac{\text { gross income at age } 62}{\text { gross employment earnings at age } 60}$

$\downarrow$ Measure the numerator and denominator over broader measurement period (while accounting for inflation)

$=\frac{\sum_{x=62}^{\text {death }-1} \text { real gross income at age } x /(\text { age of deat } h-62)}{\sum_{x=31}^{60 \text { (middle } 20 \text { years })} \text { real gross employment earnings at age } x / 20}$

$\downarrow$ Measure at the family level and then adjust for family size

$\sum_{x=62}^{\text {death }-1}[($ real gross income of family $) / \sqrt{\text { Family size }}]$ at age $x /($ age of death -62$)$

$=\frac{\left.\sum_{x=30}^{60(m i d d l e ~} 20 \text { years }\right)}{(\text { real gross employment earnings of family }) / \sqrt{\text { Family size }}] \text { at age } x / 20}$

$\downarrow$ Use a fuller measure of income available for consumption expenditure (as outlined in Figure 1)

$=\frac{\left.\sum_{x=62}^{\text {death-1 }}[\text { (real income for family consumption expenditure }) / \sqrt{\text { Family size }}\right] \text { at age } x /(\text { age of death-62) }}{\sum_{x=30}}$

$\sum_{x=30}^{60}($ middle 20 years $)[$ (real income for family consumption expenditure $\left.) / \sqrt{\text { Family size }}\right]$ at age $x / 20$

$=$ LSRR from Equation (2)

Integrated data that covers all aspects of Figure 1 are not available in Canada. This study is able to include most components (Figure 1 italicizes the missing elements) by building on Statistics Canada's LifePaths model.

In constructing the LSRR for the purpose of this study, we do not model differences in individual preferences or changes in expenses over the life course. These considerations generally fall outside the basic earnings replacement rate framework when examining populations, although they can be critical to personal retirement financial planning. They can be incorporated in the LSRR by including the changing expenses in its numerator and/or denominator this is illustrated with "work expenses" in Figure 1, for example, although we do not model this changing expense in our analysis (see Appendices C.6 and C.7 for further discussion on these considerations). Additional components of consumption not incorporated in Figure 1 that could be relevant to retirement income adequacy include (1) income in-kind - that is, goods produced by households for their own consumption, such as housekeeping, child-rearing and cooking (for a discussion on the value of home food-production for seniors, see Aguiar and Hurst, 2005; Brzozowski and Lu, 2010); (2) the flow of services from durable goods (other than just owner-occupied housing) purchased while working but consumed after retirement; (3) irregular inter-household transfers in kind (gifts) and (4) social transfers in-kind - i.e., goods provided by the public sector such as hospital and medical care services, police, parks and roads. There are a number of difficulties when attempting to include any of these four additional considerations, and these difficulties are sufficiently widespread that 
these components are conventionally not incorporated, although analysts may wish to include them depending on the purpose of their investigation and the availability of data. The Canberra Group (2001), an international expert group on household income statistics, concluded that "it is difficult to find a metric by which it would be possible to say by how much greater expenditure on defense or on road-building increased the well-being of the inhabitants. Because of this difficulty, it is not usual to include the level of government collective services in income comparisons" (22) and "( $\mathrm{t}$ )he treatment of irregular inter-household transfers in kind - gifts - is another issue raised but not resolved" (110), in its report that prescribes best practices for the production of household income statistics (primarily for the measurement of economic well-being).

Figure 1 includes some items that our study precludes on conceptual grounds, although analysts building the LSRR may wish to include them. This includes the assumption that seniors will not draw down housing equity to support consumption. Canadian seniors are much less likely to move from (and sell) their home than any other age group (Clark, 2005), and the take-up of financial instruments that draw on housing equity (such as reverse mortgages) is rare in Canada (Chiuri and Jappelli, 2010). Similarly in the United States, American seniors typically do not spend down the housing asset. For the most part, the elderly are unlikely to move or draw on housing equity to support consumption after retirement, except after major life transitions (such as the death of a spouse or illness), despite the fact that housing equity is most often a retirees' largest asset (other than Social Security and sometimes employer pension plan) (Venti and Wise, 2001, 2004). This suggests that housing equity is not generally viewed as a source of consumption, but as contingency savings to be used in the event of large and unforeseen expenses.

We also do not include "post-retirement" employment earnings since the very purpose of a "replacement rate" concept is to evaluate the extent that employment living standards have been replaced after retirement (where retirement is the cessation of employment) (see Appendix $\mathrm{C}$ for further discussion). Clearly, on an individual financial planning level, an analyst building a personalized LSRR would want to include post-retirement employment earnings to account for any work that the individual subject plans to do in retirement, health permitting, as well as the drawdown of home equity if the individual plans to sell his/her home. As already noted, moreover, the LSRR can be further tailored to fit an individual's personal circumstances/preferences by including other anticipated income sources (i.e., large gifts) and changes in expenses, as well as aiming for a higher/lower standard of living after retirement by setting the target at more/less than $100 \%$. The analyst can also include intended bequests (by removing the bequest amount from net worth) as well as continued savings after retirement. Section 5 discusses these practical considerations further, and Appendix $\mathrm{C}$ reviews these various issues when building replacement rates.

We convert wealth stocks into an income-flow at retirement by assuming a life-only inflation-indexed annuity for all individuals (whether single or non-single). ${ }^{10}$ The replacement rate calculation is simplified by assuming that 
savings are annuitized at retirement, and this simplifying assumption is the norm in replacement rate literature (for example, see Gustman and Steinmeier, 1998; Munnell et al., 2006, 2007a, 2007b). If retirement income flows are taken only in the first year of retirement (see Equation (1)), for example, assuming that personal savings are annuitized enables a straightforward comparison between employees with DB pension plans and those with DC accounts. Using inflationindexed annuities keeps the income flows from wealth on par with those retirement income flows that are also inflation-adjusted (C/QPP, OAS, GIS and inflation-adjusted employer DB pension benefits).

In actual fact, however, voluntary annuitization is extremely rare - see Milevsky and Young (2007) and Brown (2009) for U.S. evidence, and James et al. (2001) for international - and inflation-indexed annutization is nearly non-existent (indeed the authors were unable to locate a Canadian insurer who offered this product). Since people generally do not voluntarily annuitize, the mortality premium underlying annuity pricing will, on the whole, overstate the observed flow of gross income from wealth. The assumption of annuitization understates the post-retirement financial risks that retirees actually face - such as inflation rate uncertainty, financial market risks and longevity risk, thereby attenuating our results. As noted in Vanderhei (2004) and Scholz and Seshadri (2009), the shift from DB to DC pension plans among employers has complicated the replacement rate measurement since calculating an "income" from a DC account requires behavioral drawdown assumptions (while the income from a DB pension benefit is prescribed, and does not carry the risks associated with the DC income streams). The increasing proportion of DC pension plans leaves retirees more exposed to financial market volatility, both in capital value and returns to assets owned, leading to a large range of possible future outcomes. A challenge for future researchers is to decide how to handle these various risks, either within or outside the replacement rate framework (Appendix C.4 discusses the pre- and post-retirement risks not well captured in the replacement rate framework, and possible approaches for incorporating them in the study of replacement rate adequacy). Given these issues, an analyst building the LSRR may choose to assume another drawdown strategy, depending on the purpose of the measure and prior knowledge on the individual subject's drawdown preferences.

\subsection{Sample}

The conventional earnings replacement rate framework norm assumes the complete cessation of employment at a single age of retirement. Since our purpose is to understand whether the traditional $70 \%$ target does in fact maintain workinglife living standards after retirement without continued employment, this analysis does not incorporate the growing trend to partial retirement and part-time work among older workers - for example, Quinn (1999) estimates that 33\%$50 \%$ of older Americans use bridge jobs between a full-time career and complete retirement. (Note that, unlike the conventional earnings replacement rate, the 
LSRR accomodates partial retirement and part-time employment of seniors in its calculation, as Section 3.3 discussed.). We therefore include in our sample only those working individuals who cease employment after retirement, which we assume is employment of $25 \%$ or less of any fiscal year. We define retirement as the transition from working at least $75 \%$ to less than $25 \%$ of the year. ${ }^{11}$ Defining retirement by reduction of hours worked is a commonly used approach in literature (see Denton and Spencer (2009) for an international review on retirement concepts and measures).

With this definition of retirement, we examine the continuity of living standards using the LSRR (given in Equation (2) and explained in Figure 1) for individuals with a $65 \%-75 \%$ earnings replacement rate (given in Equation (1) and repeated here):

$$
\text { replacement rate }=\frac{\text { gross (i.e., before-tax) retirement income in the first fiscal year of retirement }}{\text { gross pre-retirement final employment earnings in the last fiscal year before retirement }},
$$

where employment earnings are made up of wages and self-employment gross income, and gross retirement income consists of

- the retirement benefits from

- the Canadian federal pension system (Canada/Quebec Pension Plan, Guaranteed Income Supplement, and Old Age Security);

- any occupational DB pension plan(s);

- notional annuity income from registered savings - single-life inflationindexed annuity, purchased at retirement with any registered personal savings (Registered Retirement Savings Plans) and occupational DC pension plan wealth.

Since retirement generally occurs partway through a financial year (the most popular month being June in Canada (Schwartz, 2010)), incomes are calculated for the full year preceding and following the age of retirement.

Our sample consists of simulated individuals born between 1951 and 1958, who reside in Canada from at least age 35 onward, and who retire at age 61 (the median retirement age in Canada between 2001 and 2009 has ranged from 60.6 to 61.9 years (Schwartz, 2010)).

The first column of Table 1 presents the broad characteristics - gender, marital status, work sector and education — of our sample (1951 — 1958 birth cohort retiring at age 61 with a $65 \%-75 \%$ conventional earnings replacement rate as given in Equation (1)). Among the simulated 1951-1958 birth cohort who are "working" at age 60 (i.e. employed more than $75 \%$ of the weeks within the fiscal year), just over $4 \%$ retire at age 61 (that is, did not work for more than $25 \%$ of any subsequent fiscal year), and 5.4\% of this group have a conventional earnings replacement rate between $65 \%$ and $75 \%$. Reducing the broader population to the sample that we want to address resulted in a much smaller sample size (3,122 workers). Our conclusions cannot speak, therefore, meaningfully to the 
TABLE 1

CHARACTERISTICS OF (1) 1951-1958 BIRTH COHORT OF SIMULATED INDIVIDUALS WHO RETIRE AT AGE 61 WITH 65\%-75\% CONVENTIONAL EARNINGS REPLACEMENT RATE; (2) 1951-1958 BIRTH COHORT OF SIMULATED INDIVIDUALS WHO RETIRE AT AGE 61 AND (3) ENTIRE 1951-1958 BIRTH COHORT OF SIMULATED INDIVIDUALS.

\begin{tabular}{lccc}
\hline \hline & \multicolumn{2}{c}{$1951-1958$ Birth Cohort } \\
\cline { 2 - 4 } & $\begin{array}{c}\text { Those Who Retire } \\
\text { at Age 61 with 65\%-75\% } \\
\text { Conventional } \\
\text { Replacement Rate }\end{array}$ & $\begin{array}{c}\text { Those Who } \\
\text { Retire at } \\
\text { Age 61 }\end{array}$ & $\begin{array}{c}\text { Entire } \\
\text { Birth } \\
\text { Cohort }\end{array}$ \\
\hline Household & & & \\
Single Male & $11 \%$ & $12 \%$ & $11 \%$ \\
Single Female & $19 \%$ & $15 \%$ & $14 \%$ \\
Member of Couple & $69 \%$ & $73 \%$ & $74 \%$ \\
Sector & & & \\
Public & $24 \%$ & $18 \%$ & $17 \%$ \\
Private & $76 \%$ & $82 \%$ & $82 \%$ \\
Education & & & \\
Less than High School & $9 \%$ & $17 \%$ & $23 \%$ \\
High School Graduate & $33 \%$ & $29 \%$ & $25 \%$ \\
Certificate (Non-University) & $31 \%$ & $33 \%$ & $29 \%$ \\
University Degree or Certificate & $27 \%$ & $21 \%$ & $23 \%$ \\
\hline \hline
\end{tabular}

Note: $1 \%$ of the entire birth cohort never worked (therefore, do not receive the private- nor public-sector classification).

retirement preparedness of Canadians in general. The sample does, however, serve its purpose to test the continuity of living standards for a sample of workers who achieve approximately a $70 \%$ conventional earnings replacement rate (a target that assumes the complete cessation of employment at a single age of retirement - an assumption that our reduced sample size suggests is unrealistic).

Table 1 compares the characteristics of the 1951-1958 birth cohort of simulated individuals who retire at age 61 with a $65 \%-75 \%$ conventional earnings replacement rate, to those who retire at age 61 (with any conventional earnings replacement rate level) as well as to those of the entire birth cohort. The sample under examination is largely consistent with the broader birth cohort, except its members are somewhat more highly educated and more likely to work in the public sector (the sector status is assigned at age 60).

\section{Results}

\subsection{Result \#1 — a wide range of living standards continuity}

Figure 2 plots the distribution of the LSRR for the 1951-1958 birth cohort of simulated individuals retiring at age 61 with a $65 \%-75 \%$ conventional earnings 


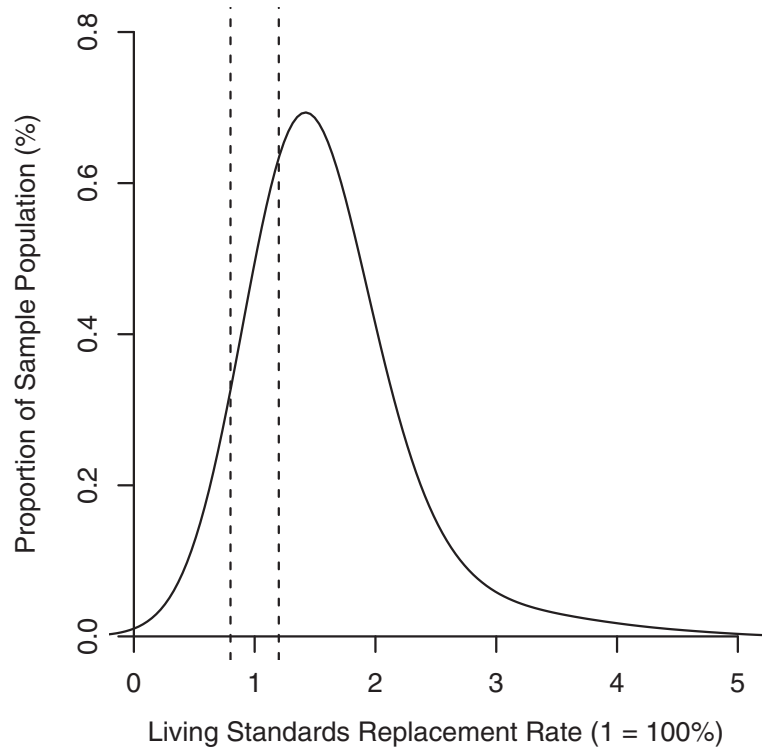

FIGURE 2: Distribution of working-life living standards replacement rates after retirement for the 1951-1958 birth cohort of simulated individuals retiring at age 61 with a $65 \%-75 \%$ conventional earnings replacement rate. (Distribution smoothed using a Gaussian kernel with a bandwidth based on normal distribution approximation. ${ }^{12}$ )

Notes: Living Standards Replacement Rate is this paper's measure of living standards continuity between working-life and retirement (see Equation (2)). The horizontal bars enclose the range of approximate living standards continuity $(80 \%-120 \%)$. Note that the smoothing causes the left tail of the distribution to incorrectly fall below zero.

replacement rate. The two dotted lines mark the LSRR at $80 \%$ and $120 \%$ (the assumed range of living standards continuity - see Section 3.3). As Figure 2 shows, most of those people satisfying the narrow $65 \%-75 \%$ earnings replacement rate criterion can actually expect to improve their living standards after retirement (but to various degrees). Specifically, some $80 \%$ of the sample will improve their living standards by over $20 \%$ after retirement (that is, LSRR > $120 \%$ ).

Figure 2 primarily shows that retirees satisfying the narrow $65 \%-75 \%$ earnings replacement rate criterion can actually expect a wide range of changes in living standards after retirement. This finding was consistent across supplementary analysis that examined other samples of workers (such as those retiring at ages 65 and 70, and testing targets of $50 \%, 60 \%$ and $80 \%$ ). Moreover, the observed spread would have been even greater had the results included the risks associated with post-retirement (such as inflation and returns on investments). (Recall that our simplifying annuitization assumption effectively removed postretirement risks, although in reality voluntary-annuitization is extremely low see Section 3.3.) 
(a) Four replacement rate (RR) measures

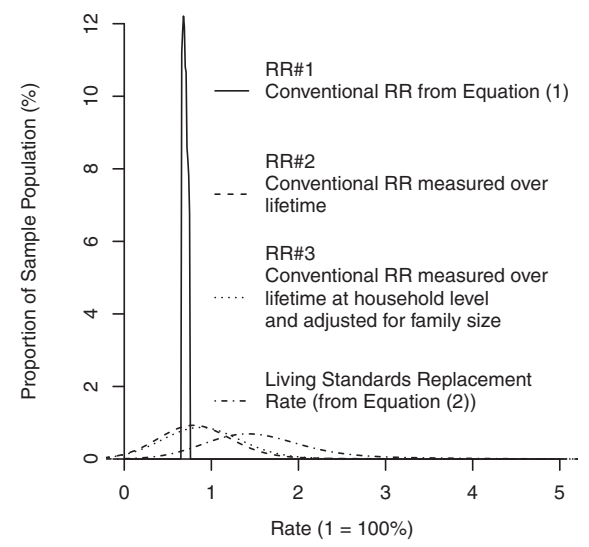

(c) Each year, measure at the household level and then adjust for family size

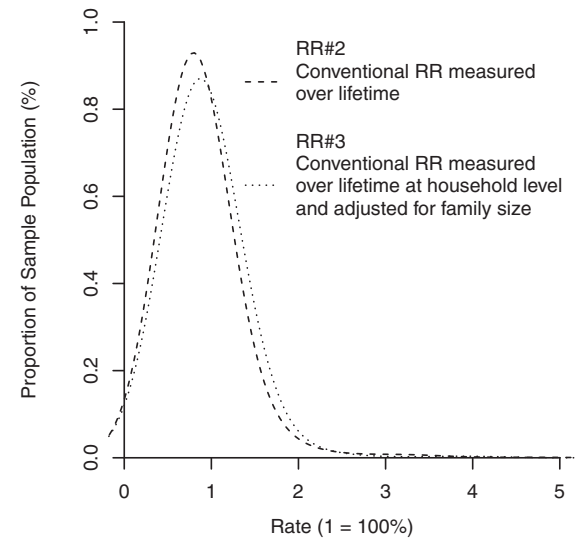

(b) Measure the numerator and denominator over broader measurement period

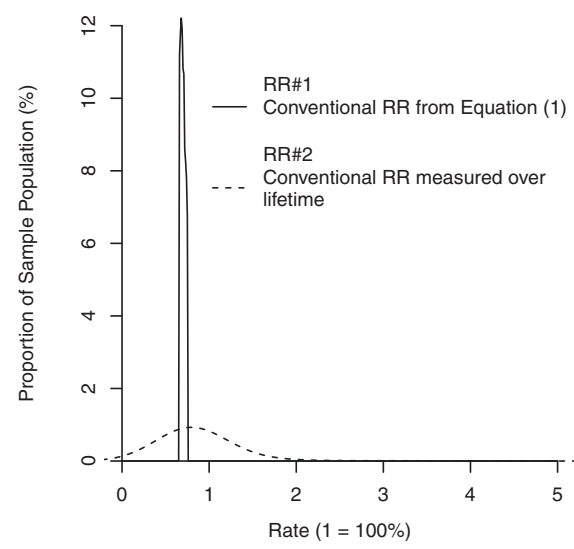

(d) Use a fuller measure of income available for consumption expenditure

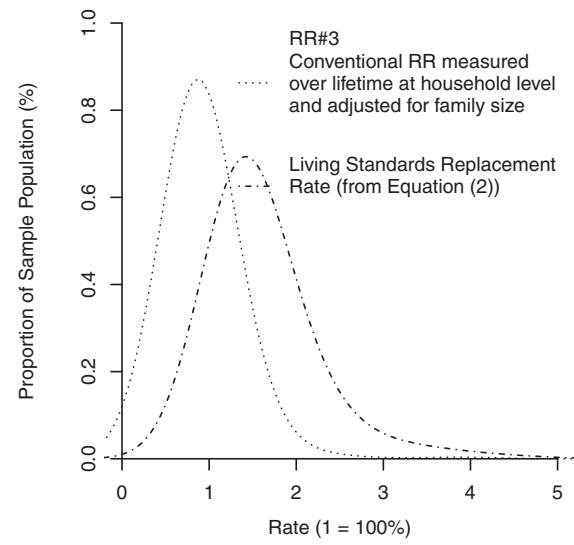

FIGURE 3: (a) Distribution of four replacement rate (RR) measures for the 1951-1958 birth cohort retiring at age 61 with a $65 \%-75 \%$ conventional earnings replacement rate. Figures (b), (c), (d) open up Figure (a), plotting each new measure one by one (and comparing it with the previous measure). (Other than RR\#1,

distributions are smoothed using a Gaussian kernel with a bandwidth based on normal distribution approximation). (a) Four replacement rate (RR) measures. (b) Measure the numerator and denominator over broader measurement period. (c) Each year, measure at the household level and then adjust for family size. (d) Use a fuller measure of income available for consumption expenditure.

Notes: Living Standards Replacement Rate is this paper's measure of living standards continuity between working-life and retirement (see Equation (2)). Conventional earnings replacement rate is the ratio of gross retirement income in the first year of retirement, divided by the subject's gross earnings in the last year of employment (see Equation (1)).

\subsection{Result \#2 - the omissions in the conventional earnings replacement rate are significant and interacting}

The people in Figure 2 started retirement with a conventional earnings replacement rate in the narrow range of $65 \%-75 \%$. The dispersion of simulated living standard continuity is striking. What is causing it? Figure 3 shows how each 
refinement to the conventional earnings replacement rate calculation from Equation (1) affects the distribution of results. Recall that Equation (1) used only a single year before and after retirement, looked exclusively at individual income and had a narrow definition of income. Section 3.3 broke down the evolution of the conventional earnings replacement rate formula into the LSRR formula using three steps - similarly, Figures 3(a)-3(d) examine the influence of measurement period, family size and income:

RR\#1: Conventional earnings replacement rate from Equation (1)

$\downarrow$ Measure the numerator and denominator over broader measurement period (as in the LSRR).

RR\#2: Conventional earnings replacement rate measured over lifetime

Each year, measure at the family level and then adjust for family size (as in the LSRR)

RR\#3: Conventional earnings replacement rate measured over lifetime at household level

Use a fuller measure of income available for consumption expenditure (as in thESRR).

LSRR from Equation (2)

Figure 3(a) graphically illustrates this progression between the conventional earnings replacement rate (RR\#1) to the LSRR by showing the distribution of these four replacement rate measures for our sample of Canadians with a $65 \%$ $75 \%$ conventional earnings replacement rate. Figures 3(b), (c) and (d) opens up Figure 3(a) to more clearly show the relative change of moving from one replacement rate concept to the next. We next discuss each in turn.

In the following discussion, recall that it is not so much the shift in the distribution that is relevant to our investigation, but the widening of the range. Under the conventional earnings replacement rate theory, retirement income adequacy occurs when approximately a 70\% target is achieved, and under our LSRR framework, it is achieved at approximately $100 \%$. Accordingly, we expect a rightward shift in the distribution when moving from one replacement rate concept to the next.

In Figure 3(b), the distribution of the conventional earnings replacement rate $(\mathrm{RR} \# 1)$ is, by definition, limited to $65 \%-75 \%$. A single year's income is the sum of permanent and transitory income; hence, broadening the measurement period by moving from RR\#1 (single year) to RR\#2 (longer period) spreads the distribution of actual replacement due to the influence of transitory income in both the numerator and the denominator of RR\#1.

To illustrate this, let $y_{x}$ represent permanent income at age $\mathrm{x}$ and $\sigma_{\mathrm{x}}$ represent the transitory component at that age, where $\sigma_{\mathrm{x}}$ is drawn from a mean zero random distribution $\mathrm{f}(\mathrm{x})$. Observed annual income at age $x$ equals to $y_{x}+$ 
$\sigma_{\mathrm{x}}$. When observed annual income is used to define the $70 \%$ target at retirement age 61, Equation (1) states that retirement income adequacy occurs when $\left(\frac{y_{62}+\sigma_{62}}{y_{60}+\sigma_{60}}=70 \%\right)$. However, if we examine the permanent income replacement rate $\left(\frac{y_{62}}{y_{60}}\right)$ of those individuals who satisfy this $70 \%$ criterion using observed annual income, manipulation of the previous equation shows that $\left(\frac{y_{62}}{y_{60}}=70 \%+70 \% \frac{\sigma_{60}}{y_{60}}-\frac{\sigma_{62}}{y_{60}}\right)$. Since $\sigma_{60}$ and $\sigma_{62}$ are random variables that are uncorrelated by construction, effectively, these transitory components in annual income have a spreading out effect on the observed "permanent" earnings replacement rate at age 61 . The choice of measurement period plays a huge role in replacement rate outcomes, as has been observed in previous literature and discussed in Section 2.

Using the family as the unit of analysis in Figure 3(c) (RR\#2 to RR\#3) has the anticipated effect of marginally shifting the distribution of relative retirement financial well-being upward. The overall shift of the distribution is largely due to the incorporation of dependent children over the working-life. Accounting for dependent children reduces effective working-life consumption, implying that any given amount of retirement income translates into a greater improvement in living standards after retirement. Incorporating spouses also affects replacement rates - for example, low-income spouses who relied on their spouse's income during working-years (e.g., while child-rearing) will receive senior benefits from the government that will improve the household's standard of living after retirement. On the flip side, some individuals' measured replacement rate will decrease once his/her higher income spouse is accounted for. The overall impact is, however, an upward shift since living standards continuity into retirement will be higher once the calculation recognizes that workers need to share their income with dependent children. (We discuss this further in Figure 4(c).)

Finally, moving from RR\#3 to LSRR in Figure 3(d) generally improves the retiree's calculated financial well-being relative to his/her working years because (1) it reflects the preferential tax treatment for Canadian seniors (much of which comes into effect after age $65^{13}$ ); and (2) it incorporates the accumulation and drawdown of savings, which simultaneously decreases the denominator and increases the numerator of the replacement rate. Specifically, consumption expenditure is diminished by the accumulation of savings (which includes mortgage payments) during working-life, while it is elevated by the drawdown of savings after retirement. Reducing the denominator and increasing the numerator both contribute to improving the overall rate, creating the rightward shift between RR\#3 and the LSRR.

The shift of the distribution in Figure 3(d) would have been even more significant had we included any drawdown of housing equity. Owner occupied housing is the single largest net asset of most Canadians, and seniors are more likely to own their home without a mortgage than any other age group (Statistics Canada, 2006). Assuming that this asset is drawn upon in retirement would have resulted in even higher LSRRs. 
(a) Four replacement rate (RR) measures

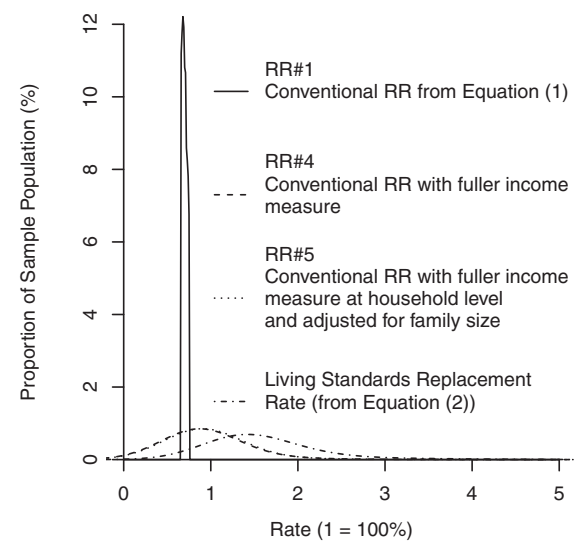

(c) Each year, measure at the household level and then adjusted for family size

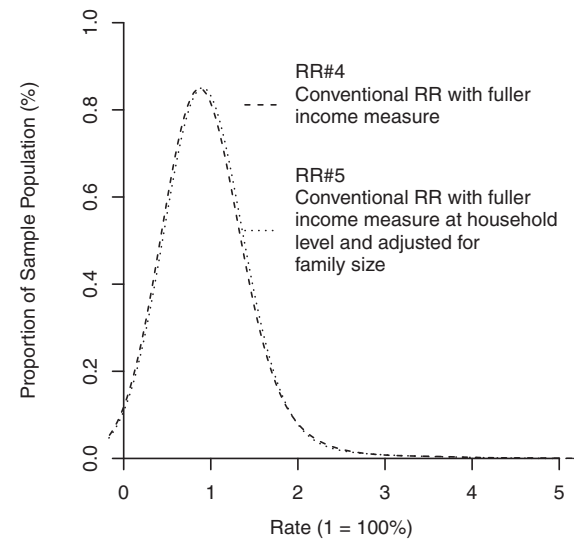

(b) Use a fuller measure of income available for consumption expenditure

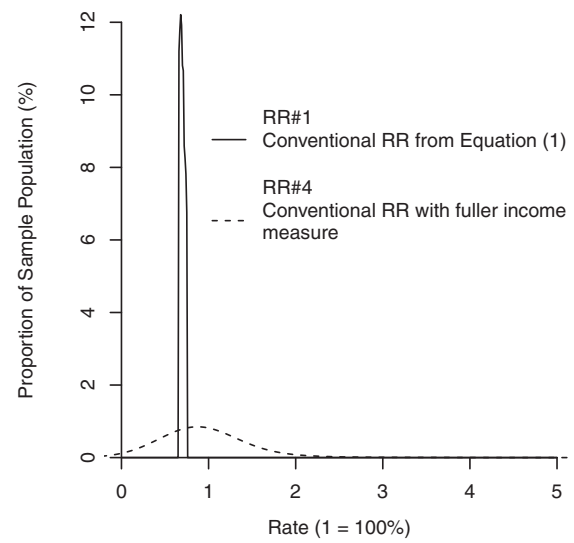

(d) Measure the numerator and denominator over broader measurement period

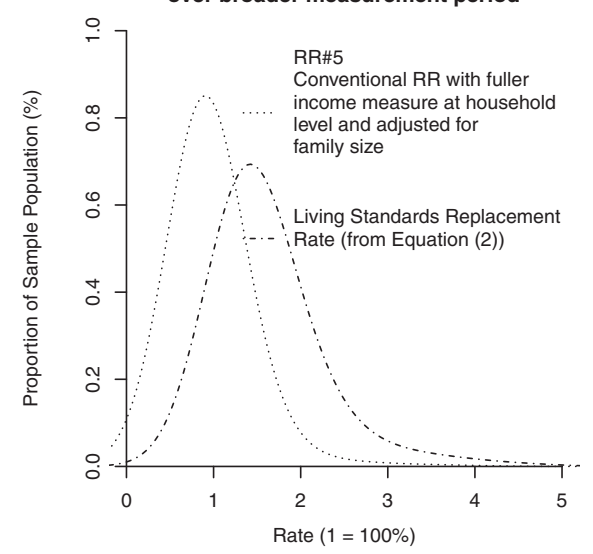

FIGURE 4: (a) Distribution of four replacement rate (RR) measures for the 1951-1958 birth cohort retiring at age 61 with a $65 \%-75 \%$ conventional earnings replacement rate. Figures (b), (c), (d) open up Figure (a), plotting each new measure one by one (and comparing it with the previous measure). (Other than RR\#1,

distributions smoothed using a Gaussian kernel with a bandwidth based on normal distribution approximation). (a) Four replacement rate (RR) measures. (b) Use a fuller measure of income available for consumption expenditure. (c) Each year, measure at the household level and then adjusted for family size. (d) Measure the numerator and denominator over broader measurement period.

Notes: Living Standards Replacement Rate is this paper's measure of living standards continuity between working-life and retirement. (see Equation (2)). Conventional earnings replacement rate is the ratio of gross retirement income in the first year of retirement, divided by the subject's gross earnings in the last year of employment (see Equation (1)).

More relevant than the shift in Figure 3(d) is the width of the distribution for the LSRR compared with RR\#3, which is created by the varying impact of including these various other sources of income in each replacement rate's numerator and denominator. One example is taxation, which is conventionally assumed fixed in replacement rate literature but has, in fact, differential impacts between people and across the life-course owing to differences in 
- the amount of total income;

- tax deductions and tax credits according to personal circumstances (such as medical expense credits for seniors with failing health);

- the composition of income by source;

- the distribution of income across spouses;

- location (since taxes vary by province);

- the forms that savings take.

It is reasonable to ask if the order of refining the conventional earnings replacement rate affects the impacts. We therefore reverse the steps by first looking at the influence of income definition on the conventional earnings replacement rate, then family size and finally measurement period. Beginning again with the conventional earnings replacement rate and ending with the LSRR, we calculate two new replacement rate measures, $\mathrm{RR} \# 4$ and $\mathrm{RR} \# 5$, using the following procedure:

RR\#1: Conventional RR from Equation (1)

$\downarrow$ Use a fuller measure of income available for consumption expenditure (as in the LSRR).

RR\#4: Conventional RR with fuller income measure

Each year, measure at the family level and then adjusted for family size (as in the LSRR)

RR\#5: Conventional RR with fuller income measure at household level

$\downarrow$ Measure the numerator and denominator over broader measurement period (as in the LSRR).

LSRR from Equation (2)

Figure 4 plots our results. Many of the same observations made for Figure 3 can be seen here.

Including all sources of income by moving from RR\#1 to RR\#4 in Figure 4(b) shifts and expands the distribution owing to the varying, and generally favorable, impacts of these other sources of income on the replacement rate.

There is minimal impact of using the family as the unit of analysis in Figure 4(c). This occurs because the measurement period is only the year before retirement (age 60), and therefore the most important family change, namely the arrival and departure of dependent children, has occurred long ago for most people. It is in Figure 4(d) that the improving impact of dependent children is realized once the measurement period is expanded (which also widens the distribution owing to the varying impact of income in these other years). This comparison illustrates the importance of including dependent children when evaluating living standards for the purpose of measuring retirement income adequacy.

The central message in Figures 3 and 4 is that the conventional earnings replacement rate is not a robust indicator of living standards continuity - for 
example, it is immensely affected by broadening the measurement period (comparing RR\#1 to RR\#2), and the income concept (comparing RR\#1 to RR\#4). It is commonly observed that there is a wide range of findings across the replacement rate literature - whether in determining the "correct" target earnings replacement rate or the proportion of the population prepared for retirement (where, "within the economics profession, there is a lot of disagreement" (Munnell, 2005: 3)). This is not surprising given that the improvements that analysts have made to the conventional earnings replacement rate measure have varied widely. (Appendix $\mathrm{C}$ reviews the various approaches taken across the literature.) Each improvement can have significant and interacting impact on the results (as Figures 3 and 4 illustrate), thus the variety of refinements made across studies have led to varying and often conflicting conclusions.

This section shows that the choices made when building the replacement rate regarding (1) unit of analysis (family versus the individual), (2) sources of consumption and (3) measurement period all have large impacts. These choices interact, moreover, and the effect of improving one may not emerge without the other. The clearest example of the interaction and significance of the omissions is in the incorporation of family size in the conventional earnings replacement rate measure and the impact of the measurement period choice. Some analysts incorporate family size into the conventional earnings replacement rate, but without simultaneously opening up the measurement period (see Appendix C.1). We find that accounting for family composition (by moving from RR\#4 to RR\#5 in Figure 4(c)) has little effect on the replacement rate distribution if using the conventional pre-retirement measurement period of one year. It is only when income is measured over years when children are dependent that the replacement rate distribution is appreciably affected by family composition (moving from RR\#5 to LSRR in Figure 4(d)). As emphasized by Scholz and Seshadri (2009), the role of children in determining preretirement living standards is crucial, although nearly universally ignored in this line of research. In future years, the increasing number of young adults living with their parents suggests that dependent children may, moreover, be a consideration both during the pre-retirement period and also after retirement. Between 1981 and 2011, the ratio of young adults (aged 20 to 29) living with their parent(s) increased from $26.9 \%$ to $42.3 \%$ (Statistics Canada, 2011).

\subsection{Result \#3 - the $70 \%$ target does not appear to fit any subgroup}

Some argue that the $70 \%$ target works for specific groups, such as the middleclass or public-sector workers, but we have not been able to locate a segment of the population for whom the $70 \%$ conventional earnings replacement rate target accurately predicts living standards continuity. Figure 5 segments the population by work sector, family type, education and individual gross employment earnings at age 60 to examine whether there is a specific characteristic(s) within the sampled population driving the wider distribution. Controlling for these 
(a) Sector at Age 60

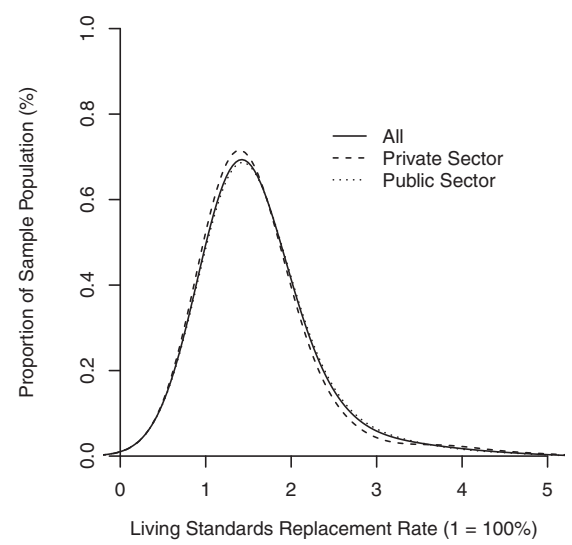

(c) Education at Age 60

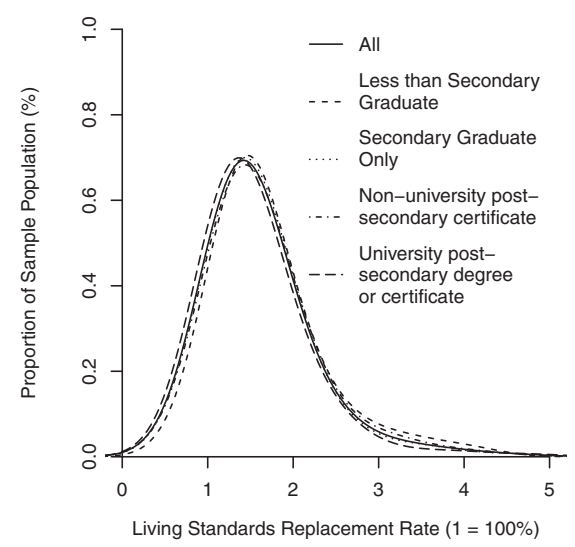

(b) Gross Employment Earnings at Age 60 (2012\$)

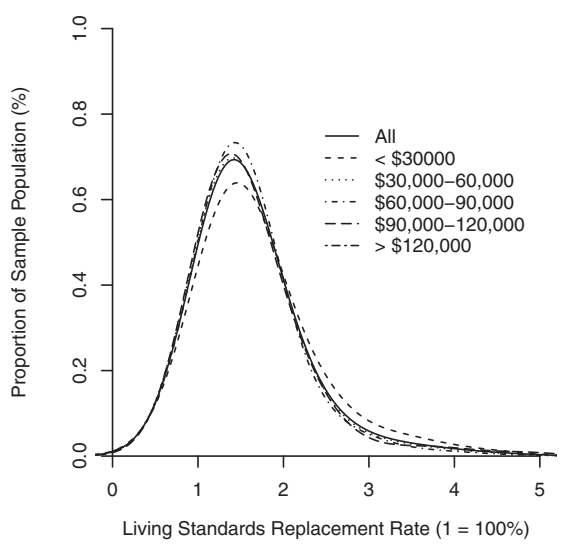

(d) Household Type at Age 60

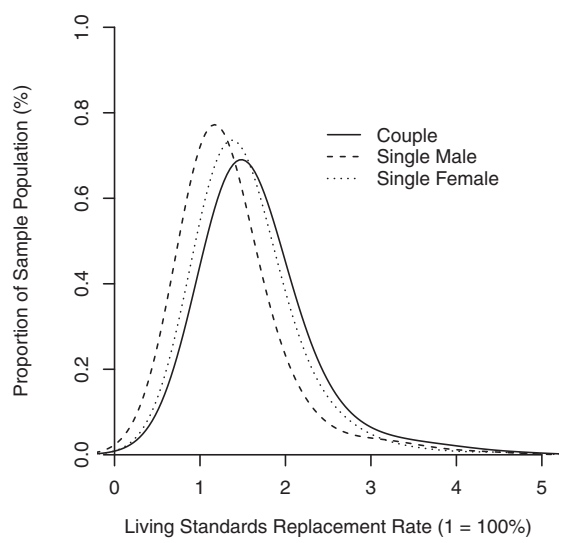

FIGURE 5: Distribution of working-life living standards replacement rates after retirement for the 1951-1958 birth cohort of simulated individuals retiring at age 61 with a $65 \%-75 \%$ conventional earnings replacement rate, by (a) work sector at age 60; (b) gross employment earnings at age 60; (c) education attainment at age 60 and (d) by household type at age 60 (distributions smoothed using a Gaussian kernel with a bandwidth based on normal distribution approximation).

Notes: Living Standards Replacement Rate is this paper's measure of living standards continuity between working-life and retirement (see Equation (2)). Conventional earnings replacement rate is the ratio of gross retirement income in the first year of retirement, divided by the subject's gross earnings in the last year of employment (see Equation (1)).

characteristics does not appreciably change the distribution of LSRRs - that is, the wide distributions remain nearly the same across the subgroups. The only noticeable impact is between singles and couples, where the distribution is shifted to the right, which is again largely a product of the more likely support of children among couples (as discussed, the general impact of incorporating children shifts the rate upward). 


\subsection{Result \#4 - the conventional earnings replacement rate and living standards continuity are poorly correlated}

Does the traditionally measured $70 \%$ earnings replacement rate offer much guidance as a retirement income adequacy target for living standards continuity? We conclude not. Among the simulated individuals who obtained a $65 \%-$ $75 \%$ conventional earnings replacement rate, only $22.5 \%$ actually achieved living standards continuity between working-life and retirement (defined as $80 \%<$ LSRR $<120 \%$ ). Once we included all the simulated individuals from that birth cohort who retired at age 61 (that is, without filtering on the $65 \%-75 \%$ conventional earnings replacement rate), we found that even a higher proportion $(28.5 \%)$ achieved living standards continuity. Testing people with lower $(60 \%)$ and higher $(80 \%)$ conventional earnings replacement rate targets produced similar results - between $20 \%$ and $30 \%$ of them achieved living standards continuity. This suggests that the conventional earnings replacement rate target has little information content.

Is there any relationship between the conventional earnings replacement rate (from Equation (1)) and living standards continuity (estimated using the LSRR in Equation (2))? If conventional earnings replacement rates had some validity, we would expect that people with higher conventional earnings replacement rates would, on average, also have improved living standards in retirement, and vice versa. This is not the case. Among the simulated individuals who retire at age 61 (not just those with a $65 \%-75 \%$ conventional earnings replacement rate), we find that the correlation (Pearson product-moment correlation) between conventional earnings replacement rates and the LSRR is only 0.11 , suggesting that the conventional earnings replacement rate formula is a very unreliable measure of living standards continuity. Indeed, Figure 6 shows that the distribution of living standards continuity given in Figure 2 remains nearly unchanged regardless of whether we had captured workers with a $50 \%, 70 \%$, or $100 \%$ conventional earnings replacement rate. The lack of movement in the distribution signifies that the earnings replacement rate simply does not predict living standards continuity between working-life and retirement.

\section{AdOPTING THE LSRR - Why, WHO AND How?}

\subsection{Why?}

"One-size-fits-all" final employment earnings replacement rate targets have historically been used widely to evaluate retirement income adequacy because comprehensive individualized measures are difficult to compute (often on account of data constraints). This paper finds, however, that any single year's employment earnings does not provide a good estimate of working-life living standards, and therefore is not a reliable benchmark for determining retirement income adequacy. If retirement income adequacy is to be meaningfully tested, it is necessary 


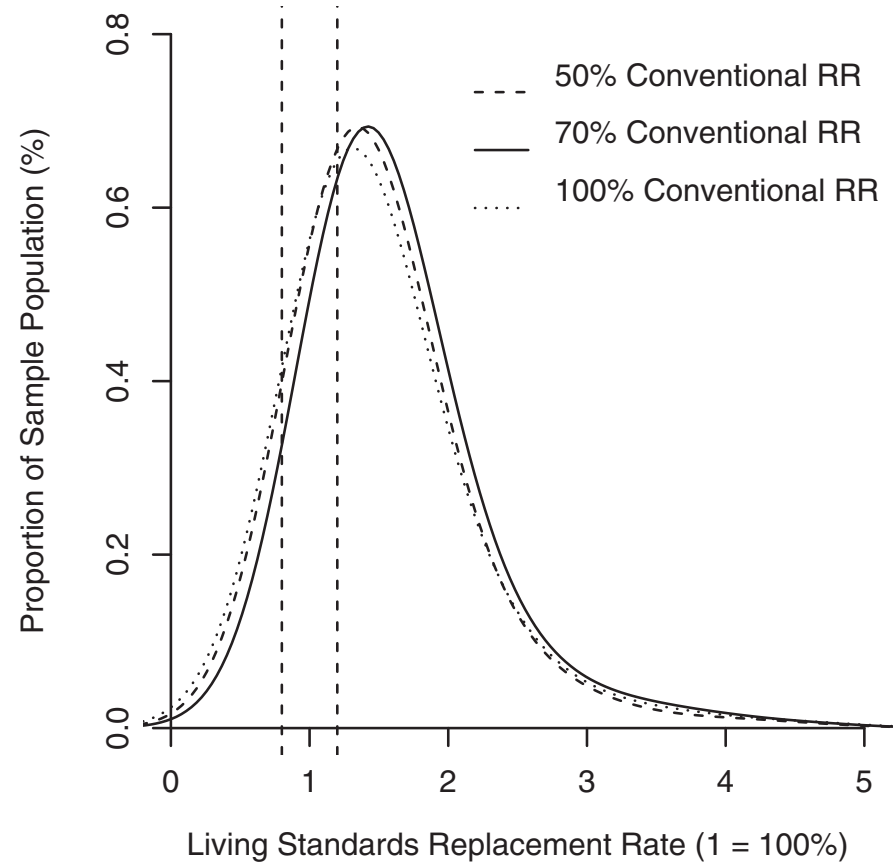

FIGURE 6: Distribution of working-life living standards replacement rates after retirement for the 1951-1958 birth cohort of simulated individuals retiring at age 61 with a conventional earnings replacement rate $45 \%-55 \%$ (dashed line), 65\%-75\% (solid line), and 95\%-105\% (dotted line). (Distribution smoothed using a Gaussian kernel with a bandwidth based on normal distribution approximation.)

Notes: Living Standards Replacement Rate is this paper's measure of living standards continuity between working-life and retirement (see Equation (2)). The horizontal bars enclose the range of approximate living standards continuity $(80 \%-120 \%)$. Note that the smoothing causes the left tail of the distribution to incorrectly fall below zero.

to develop individualized measures using more comprehensive and evidencebased assessments of pre- and post-retirement living standards.

Nearly three decades ago, Palmer (1988) developed target gross earnings replacement rates by assigning average levels of social security benefits, taxes and savings rates (based on survey data) to workers in various subgroups (differentiated by broad characteristics earnings level, region and marital status) (see Appendix B for a description of the methodology). This work led to a long line of follow-up reports, whose results have been widely disseminated. The 2008 Palmer report wrote:

For twenty years, Aon Consulting and Georgia State University have published data on retirement income needs. The Replacement Ratio Study ${ }^{\mathrm{TM}}$ has become a premier source of retirement planning information for employers, employees, and their advisors. The 2008 Replacement Ratio Study is the seventh update of this report and builds on a 1980 edition issued by the President's Commission on Pension Policy... This 2008 
update continues to answer the original question, 'How much income will I need at retirement to maintain my standard of living? Palmer (2008: 2)

A noteworthy user of these rates is the popular U.S. National Retirement Risk Index (NRRI) (Munnell et al., 2006), which has garnered substantial attention in both academia and in the media. In 2013, the NRRI study predicted that almost half of Americans are financially unprepared for retirement (Munnell et al., 2013), using Palmer's targets as its measure of retirement income adequacy.

The first issue is that these target rates omit or poorly deal with the many components of living standards discussed throughout this paper (and listed in Section 2). Second, the Palmer target rates were developed based on stylized individuals - the problems associated with stylized individuals have been discussed by, among others, Steuerle et al. (2000). Third, the authors have been unable to locate any empirical demonstration that the targets actually accomplish their goal - that is, for a sufficient sample of workers who hit these prescribed targets, living standards are, in fact, approximately maintained after retirement.

In the three decades since its inception, moreover, the underlying methodology has not changed very much. On the other hand, the world of employer pensions, family dynamics and financial market expectations have changed drastically. At one time, it may have seemed justifiable that earnings in the year leading up to retirement should be the benchmark for retirement income adequacy, as it was more common to spend entire careers with the same employer, when salaries were much more stable and DB pension plans were the norm. In addition, married couples were very unlikely to divorce after retirement and seniors were most likely cared for by family and friends in the case of chronic illness (see Appendix A for supporting evidence). This is no longer the case. Retirement income adequacy is a growing concern in Canada and industrialized countries around the world due to the low interest rate environment, high investment fees, longer life expectancies, rising divorce rates among seniors, aging populations, an increasing reliance on paid services to care for chronic health conditions, the shift from DB to DC pension plans and reduced confidence in financial markets - see Appendix A. In addition to signaling a greater need for accurate measures of retirement income adequacy, these changes in culture and the economic environment strongly suggest that the simplistic assumptions that may have underlain the conventional earnings replacement rate are insupportable.

By solely relying on employment earnings, and doing so in a single year, the conventional earnings replacement rate does not capture living standards. Housing wealth, financial debt, savings decisions, number of children and the earnings of one's spouse are among the many determinants of a person's living standards, but the conventional earnings replacement rate ignores them. Consider two male 40 year olds, who both earn $\$ 50,000$. The conventional earnings replacement rate would advise them to save enough so that their retirement 
income is $\$ 35,000$ per year (assuming that wage growth keeps pace with inflation). The first man has, however, a wife who is a homemaker, three children and rents his home (at $\$ 1,500 /$ month). The second man has a wife who earns twice his income, no children and paid off his home two years ago. Even if we make the simplifying assumption that both men saved $10 \%$ of their gross earnings, and their homes are comparable, the estimated value of the second man's personal living standard is over five times that of the first man $(\$ 85,000$ versus $\$ 16,000$, assuming 2015 average tax rates in Ontario). If both men targeted $\$ 35,000$ in retirement, the second man would experience a 70\% drop in his living standards after retirement, while the first man would increase his living standards by $70 \%$. In other words, the $70 \%$ target would have led the first man to over-save significantly (likely at the expense of his family's needs) and led the second man to under-save to a similar degree.

A second major problem when relying exclusively on a single year's employment earnings to estimate pre-retirement living standards is that the employment earnings of actual people can swing dramatically from year to year (see Section 2). So, not only is any single year's employment earnings unlikely to approximate working-life living standards, it may not even represent "typical" earnings for that individual. Consequently, in addition to the necessity to capture the full financial picture of a person's living standards (presented in Figure 1), it is also necessary to calculate average working-life living standards over a sufficiently representative number of years.

\subsection{Who and how?}

One of the primary goals typically identified for retirement income policy is that individuals should not experience substantial declines in their standard of living upon retirement - the LSRR is a measure that directly evaluates this policy goal. Another common objective of policy analysts when evaluating retirement income adequacy is to identify vulnerable groups in the population, as well as understand the diverse implications of policy features, and proposed changes, across the population. The LSRR could be employed to identify the "winners" and "losers" of policy designs by providing a meaningful measure of retirement income adequacy, where the changes in an individual's retirement living standards are compared directly to his/her own personal pre-retirement living standards (and not to a universal and misleading target). Changing LSRR values signal "who" is affected, and the degree of change measures "how much" that person is affected in relation to his/her personal living standard.

Employer pension plan sponsors may well be interested in designing a pension plan that, in conjunction with government benefits, will adequately serve a specific "target" type of employee - for example, career employees who retire at age 65 and follow a plausible, or "typical", career path. In this respect, the LSRR concept is a useful metric for understanding the true effectiveness of design formulas in serving the type of employee that the plan is targeting. When 
building the LSRR, therefore, the pension plan sponsor's analyst may choose to use "representative" levels of housing wealth, number of children, spousal earnings and other components of the LSRR suitable to the type of employee that the plan is targeting. A useful follow-up analysis would be to then use the actual data of a few sample employees to examine the validity of the stylized results. This approach would not only likely be more in line with the objectives of the plan sponsor, but would also reduce the data and modeling requirements tremendously. In fact, such calculations could be carried out deterministically with relative simplicity.

Another line of analysis would be if a plan sponsor wanted to use the LSRR to test the employee populations' ability to retire. With the greater shift to DC pension plans, where the employer has much less control within the pension plan design to encourage a particular age of retirement, understanding the true retirement preparedness of employees can help employers take proactive measures to help employees who need additional retirement planning assistance. This helps to ensure an orderly transition of the workforce and reduce other costs associated with having older employees continuing to work past an optimal age. In this type of investigation, the analyst would use individual-specific LSRR inputs for each employee when possible, and make assumptions to fill in gaps. $^{14}$

Employers could also use the LSRR to help employees test their personal level of retirement financial preparedness and make retirement savings decisions. Such a service would be very beneficial to an employee who does not fit the "targeted" employee profile, such as somebody who joins the plan later in life or wishes to retire early. Similarly, for workers saving for retirement and the financial analysts helping them, the LSRR provides guidance on how to evaluate current living standards and determine how much retirement income should be aimed for if living standards continuity is the goal. It provides a more understandable measure so that workers can better appreciate the true impact of alternative financial planning decisions on living standards continuity after retirement. Some workers may wish for better living standards after retirement (i.e., more money to spend to support personal consumption) and thus they would aim for more than $100 \%$, and the opposite may also be true.

In Canada, Eckler Ltd.'s Guided Outcomes (GO) is an industry example of a model that employs the LSRR for its DC plan sponsor clients to evaluate pension design and support participants. This model uses both deterministic and stochastic elements in its projections. In terms of personal financial planning, Avery and Morrison's (2009) Ruthen package employs the LSRR framework to compare alternative financial strategies for individuals; it uses sophisticated dynamic micro-simulation modeling that captures both consumption outcomes and the dispersion that emerges from a variety of risks.

Section 3.3 presented the LSRR framework, and discussed some additional considerations when building the LSRR for both industry and policy analysts. Readers wishing to adopt the LSRR to industry should, however, keep in mind that our tool of analysis was a large-scale micro-simulation model, and some 
components of our analysis design would be overly burdensome for industry analysis. For example, when calculating "working-life" living standards (that is, the denominator of LSRR), the general goal of the industry analyst should be to capture a representative number of years. This paper had the opportunity to look at the whole working-career (30 years) and average across the most "representative" 20 years, which is likely impractical for industry analysis. The message of this paper is that it is crucial that the calculation covers a representative number of years. Overall, "the more, the better" when capturing pre-retirement living standards, but the entire career is not necessary. When calculating "retirement" living standards in the LSRR numerator, the industry analyst will similarly aim to capture a "representative" number of years. Relative to the working life, retirement income shows much less volatility (see Appendix C-3 for further discussion). Nevertheless, employer pension plan benefits that are not indexed to inflation will increasingly lose value over time. As a result, using a snapshot of retirement income in the early years of retirement can overstate the real value of the retirement income levels. In our analysis, we averaged living standards from retirement until death, but this can be impractical for industry analysts adopting the LSRR. One shortcut is to employ a single year in retirement, but chose a later age, such as age 75 . Using a later age incorporates some of the eroding effect of inflation over retirement, as well as avoids having to deal with the complicated transition years between employment and retirement (such as part-time employment and partial retirement benefits).

A further question when applying the LSRR is the treatment of high-/lowincome workers when assessing the retirement preparedness of employer pension plan participants. The LSRR is a relative measure, and therefore for people who were poor during their working years, "continuity in living standards" means being poor in old age too (in other words, continuity does not imply true adequacy). Similarly, the relative LSRR measure may fall below $100 \%$ for affluent workers who would otherwise be viewed as adequately prepared for retirement. One approach is to combine the relative LSRR measure with an absolute "low" and "high" measure of retirement living standards. For example, the analyst could flag individuals whose LSRR numerator falls below an absolute value intended to signal poverty (such as the "HRSDC Market Basket Measure", which represents the basic cost of necessities for individuals living in Canada) or above an absolute measure whose value is deemed adequately sufficient to support an affluent standard of living. The treatment of low- and highincome employees depends largely on the goals of the pension plan sponsor.

A common concern when applying the LSRR to industry has been "imputed rent". While academic analysis tends to include theoretical consumption, practitioners and individuals who are planning for retirement tend to think in terms of cash flow needs. Although not commonly used in industry, imputed rent is an important consideration in the analysis of retirement income adequacy since it enables analysts to incorporate the differing financial situations of a homeowner versus a non-homeowner. In terms of actual cash flow needs, it accounts for the freed-up "money to support personal consumption" of a 
homeowner who does not need to pay rent for his/her shelter, and therefore a relevant and recommended component of the living standards calculation (see Appendix C.2 for further discussion on imputed rent).

A final comment is that the future is uncertain, so the LSRR values (like any metric) should be routinely reassessed and inputs adjusted to recognize actual experience.

\section{CONCLUSION}

The conventional final employment earnings replacement rate is a widely used benchmark to evaluate retirement income adequacy, commonly employed by public policy analysts, employer pension plan advisors and academics when evaluating the retirement preparedness of a population or comparing pension systems, as well as by financial advisors and individuals making retirement financial planning decisions. It underlies pension systems, drives the research that determines whether populations are prepared or not prepared for retirement, and is the backbone of retirement planning software. Our analysis finds that it predicts living standards continuity in retirement very poorly.

Specifically, we find that workers who approximately attain a final employment earnings replacement of $70 \%$, - i.e., actually hit the "right" target — will experience a wide range of living standards continuity after retirement. This is problematic at both extremes - both for those who end up experiencing relative deprivation in retirement and for those whose relatively high consumption during their retirement years was purchased by the over-sacrifice of working-life welfare. We have been unable to locate a segment of the population for whom the $70 \%$ target accurately predicts standard of living continuity.

This paper finds that the conventional earnings replacement rate is a poor metric for understanding how well an individual's living standards are maintained after retirement. The primary reason is that a single year's employment earnings are not a reliable representation of working-life living standards. The conventional earnings replacement rate formula relies on an inadequate measurement period, does not incorporate important components of consumption, and ignores family size. These omissions are crucial to accurate estimation of pre-retirement living standards. Further, we find that these omissions interact, and refining the conventional earnings replacement rate measure requires simultaneous improvement in all three of these spheres since the full effect of improving one may not emerge without the others. These significant and interacting omissions have led to a wide range of often conflicting reports on the retirement preparedness of populations.

Analysts have suggested that the use of single replacement rate "targets" are not reasonable owing to the existence of risk, and our results go beyond this and suggest that the conventional earnings replacement rate has little predictive value owing to its omission of critical components of living standards in its formula. Our paper demonstrates that before one can decide whether 
living standards in retirement are adequate or inadequate, one needs a measure that accurately measures living standards both before and after retirement.

Replacement rate statistics play an important role in providing a single statistical criterion for retirement income adequacy, and the authors recognize the importance of "Not throwing the baby out with the bathwater". Accordingly, this paper suggests the LSRR as an alternative metric for assessing how well a worker's living standards are maintained after retirement. The LSRR is a more accurate, understandable, and consistent measure of living standards continuity for the purpose of measuring retirement income adequacy. The goal of the LSRR is to determine how well a worker's living standards will be maintained after retirement, by comparing how much money a worker has available to support his/her personal consumption of goods and services before and after retirement. As outlined in this paper, it is crucial that the LSRR calculation considers the entire family, includes consumption components comprehensively and covers a representative number of years.

The framework presented in this paper is intended to provide a guide for academics, financial planners, employer pension plan advisors and policy makers to follow when analyzing individuals or populations. While the conventional earnings replacement rate has been calculated in a wide variety of ways, the LSRR framework will enable a more consistent measure of retirement income adequacy that analysts can reference, which will facilitate the interpretation, comparison and integration of findings across different analysis (between authors, over time and across nations), greatly helping the study of retirement income adequacy to move forward.

Employer pension plan sponsors could use the LSRR to investigate the retirement income adequacy provided by their pension plan and savings program for the "typical" type of employee that the plan is targeting, test the true effectiveness of adopting different plan features, assess the level of retirement preparedness among its plan participants, and engage plan participants to help them better appreciate the true impact of alternative financial planning decisions on their living standards after retirement. Policy analysts could use the LSRR to evaluate the retirement income adequacy of their current system across the population, identify vulnerable groups, and understand the implication of policy changes. Financial advisors could use the LSRR as a retirement income target that clients can understand when making financial planning decisions. The LSRR can be computed with sophisticated dynamic stochastic micro-simulation modeling, simple deterministic projections or something in between. In all of these roles, the analysts will inevitably run into gaps in the data, which they will need to fill. Nevertheless, data constraints should not create a barrier to adopting the LSRR. It is far better to acknowledge and grapple with weaknesses and gaps, and make informed assumptions when necessary, than to blindly rely on simplistic and invalid benchmark targets. Analysts invest significant time and effort in the study of retirement income adequacy, but employing an unreliable benchmark for "adequacy" not only effectively invalidates that effort, but it can also lead to misleading, and possibly harmful, conclusions. 
With population aging in many industrialized countries, now more than ever is the time to adopt better measures of retirement income adequacy.

\section{ACKNOWLEDGEMENTS}

We would like to thank Malcolm Hamilton, James Davis, Deborah Ng, Fred Vettese, Keith Ambachtsheer, Rob Brown, Richard J. Morrison, Janice Holman, Eckler Ltd, and the Economics Department of Dalhousie University. We also wish to thank an anonymous reviewer for his/her helpful comments. This project began in response to a call for proposals by the Society of Actuaries' Pension Section over five years ago, and we gratefully acknowledge their financial support and the feedback given by the project oversight group on earlier drafts. This paper was helped funded by the Rotman International Center for Pension Management (ICPM) at the Rotman School of Management, University of Toronto, whom we thank. We thank the ICPM review committee for their valuable feedback. Finally, progressive versions of this work was presented at the following gatherings, and we thank and acknowledge the organizers of these events and the valuable feedback from its audiences: NEST Insight 2016 Conference, Benefits Canada 17th Annual Defined Contribution Plan Summit (2016), Association of Canadian Pension Management Panel Discussion (2016), Rotman International Centre for Pension Management 2014 Discussion Forum, 30th International Congress of Actuaries (2013), Towson University Actuarial Science 2013 Annual Colloquium, North America Society of Actuaries Webcast Speaker on Retirement Income Adequacy (2012) and 2011 Canadian Institute of Actuaries Pension Seminar, Toronto. An earlier draft of this paper won the ICA 2014 Pension, Benefits and Social Security Scientific Committee Award Prize for Best Paper at the 30th International Congress of Actuaries in April 2014.

\section{NOTES}

1. Appendix A discusses each of these seven factors.

2. Between 2001 and 2009, the median retirement age for Canadians has ranged from 60.6 to 61.9 years (Schwartz, 2010).

3. The opinions expressed and conclusions reached by the authors are their own and do not represent any official position or opinion of Statistics Canada. We take full responsibility for the assumptions underlying the projection scenario used.

4. Examples of studies that prescribe or depend on replacement rates as a criterion for retirement income adequacy (in terms of living standards continuity) include Dexter (1984), Boskin and Shoven (1987), Palmer (1988, 2008), Gustman and Steinmeier (1998), Mitchell and Moore (1998), Moore and Mitchell (2000), Alford et al. (2004), Schieber (2004), Steinberg and Lucas (2004), Vanderhei (2004), Munnell and Soto (2005), Haveman et al. (2006), Munnell et al. (2006), Munnell et al. (2007a, 2007b), OECD (2009), Brady (2010), Dodge et al. (2010), McGill et al. (2010), TD Economics (2010), Munnell et al. (2011), U.K. Government DWP (2013) and Shillington (2016).

5. Sustaining living standards after retirement is the most prevalent definition of retirement income adequacy in the replacement rate literature (see footnote 4 for samples of published research), although not the universal one. Engen et al. (1999) and Scholz and Seshadri (2009) are examples of authors who employ replacement rates but apply a utility maximization framework in an augmented life-cycle model. They argue that retirement income adequacy occurs when the discounted marginal utility of consumption is smoothed over time. 
6. While replacement rates are most commonly used as a prescriptive statistic that signals retirement income adequacy, they have also been used as a descriptive statistic to examine trends over time and between groups of people (e.g., Boskin and Shoven, 1987; GAO, 2001; Smith, 2003; Butrica et al., 2003; Fidelity, 2007; LaRochelle-Cote et al., 2008; Ostrovsky and Schellenberg, 2009).

7. In Canada, "registered" plans (such as Registered Retirement Savings Plans (RRSPs) and Registered Retirement Income Funds (RRIFs)) are tax-sheltered retirement savings, where contributions and investment returns are tax-exempt while taxation occurs when the funds are withdrawn.

8. To capture the income pooling and economies of scale that individuals experience within a household, a commonly used equivalence scale is the square root of household size (Buhmann et al., 1988), i.e., if two households had the same income $(\$ X)$, but one was a single-person household and the other had four members (e.g., two adults and two children), then the equivalent income of the person in the one-person household would be $\$ X$, while each person in the four-person household would be assigned an equivalent income of $\$ X / \sqrt{ } 4=\$ X / 2$. Note that we measure at the census-family level as LifePaths does not model economic households.

9. A drop in necessary expenditure after retirement to sustain pre-retirement living standards is also suggested by research explaining the "retirement consumption puzzle", which finds that retirement provides additional leisure time for home-production, which lowers the expense of maintaining working life living standards (Aguiar and Hurst, 2005; Brzozowski and Lu, 2010).

10. For annuities purchased with non-registered funds, we assume the Canadian 2012 taxation treatment of "prescribed annuities" (calculating the taxed amount as a proportion of the annuity payment). Owing to the inflation indexation assumption, however, the appropriate tax rate would depend on the more complex treatment of "non-prescribed annuities" (see Milevsky, 2010 for further information). However, the empirical impact of this simplifying assumption is trivial.

11. For the purpose of federal employment insurance benefits, Canadians are considered "attached" to the labor force if they have worked 490 hours in the previous year (which is $24 \%$ of the year assuming a standard 40 hour work-week), thus leading to the choice of $25 \%$ in our retirement concept. Source: www.servicecanada.gc.ca/eng/ei/types/regular.shtml\#Number

12. Wikipedia provides a good explanation of kernel smoothing, which includes a description of Gaussian kernel smoothing (https://en.wikipedia.org/wiki/Kernel_smoother\#Gaussian_ kernel_smoother)

13. In 2013, these advantages included: the splitting of certain types of income from pensions and registered savings between Canadian spouses; up to 6,854 of personal federal income tax exemption for people 65 years plus; a federal tax-exemption for the first 2,000 of pension income; the exemption of Guaranteed Income Supplement (low-income senior benefit) and corresponding provincial/territorial exemptions.

14. For example, Canadians have approximately two children on average, so this would be a reasonable assumption in the absence of data. The analyst may wish to test the impact of assuming more or less children, and the implications for adequacy. Similarly, most Canadians own a home at retirement, so the analyst could use regional housing prices to assign housing values by earnings. The LSRR calculation is simplified further if the employer pension plan sponsor is interested in the adequacy of the pension plan (combined with government benefits) without depending on supplementary individual savings from employees. In this case, the analyst simply assumes no savings/debt in the LSRR calculation, which would eliminate the necessity to collect that data (or otherwise input assumptions).

15. "Earnings mobility refers to changes in the relative earnings of individual workers through time" (Beach and Finnie, 2004: 5).

16. See, for example, the line of research by the Society of Actuaries Committee on PostRetirement Needs and Risks at http://www.soa.org/research/research-projects/pension/researchpost-retirement-needs-and-risks.aspx

\section{REFERENCES}

Aguiar, M. and Hurst, E. (2005) Consumption versus expenditure. Journal of Political Economy, 113(5), 919-948. 
Alford, S., FARnEn, D.B., and SCHACHET, M. (2004) Affordable Retirement: Light at the End of the Tunnel. Benefits Quarterly, 20(4), 7-14.

AVERY, M. and MORRISON, R.J. (2009) Spending down one's retirement assets in an uncertain world. Prepared for the June 2009 Meetings of the International Microsimulation Association, Ottawa, Ontario, Canada.

BALDWIN, B. (2009) Research study on the Canadian retirement income system: Final report. Prepared for the Ministry of Finance, Government of Ontario.

BEACH, C. and FINNIE, R. (2004) A longitudinal analysis of earnings change in Canada. Canadian Journal of Economics, 37(1), 219-240.

Bernheim, B.D., Forni, L., Gokhale, J., and Koltikoff, L.J. (May 2000) How Much Should Americans Be Saving for Retirement? American Economic Review, 90(2), 288-292. doi:10.1257/aer.90.2.288.

BigGS, A.G., and SpRINGSTEAD, G.R. (2008) Alternate Measures of Replacement Rates for Social Security Benefits and Retirement Income. Social Security Bulletin, 68(2), 1-19.

BINSWANGER, J. and SCHUNK, D. (2012) What is an adequate standard of living during Retirement?. Journal of Pension Economics and Finance, 11(2), 203-222

Boskin, M. and SHOven, J.B. (1987) Concepts and measures of earnings replacement during retirement. In Issues in Pension Economics. (eds. Z. Bodie, J.B. Shoven and D.A. Wise), Chicago: University of Chicago Press.

BRADY, P. (2010) Measuring retirement resource adequacy. Journal of Pension Economics and Finance, $9(2), 235-262$.

BRANCATI, C.U., BEACH, B., FRANKLIN, B., and JONES, M. (2014) Understanding Retirement Journeys: Expectations vs. Reality. London: International Longevity Centre UK. November.

BROWN, J.R. (2009) Understanding the role of annuities in retirement planning. In Overcoming the Saving Slump (A. Lusardi ed.), Chicago: University of Chicago Press.

BRown, S.L. and LIN, I.-F. (2012) The gray divorce revolution: Rising divorce among middleaged and older adults, 1990-2010. Journals of Gerontology Series B: Psychological Sciences and Social Sciences, 67(6), 731-741.

BRown, W., HOU, F. and LAFRANCE, A. (2010) Incomes of retirement-age and working-age Canadians: Accounting for home wwnership, Statistics Canada Economic Analysis Research Paper Series, Ottawa, July 2010.

BRZOZOWSKI, M. and LU, Y. (2010) Home cooking, food consumption, and food production among retired Canadian households. Canadian Public Policy, 36(1), 107-128.

Buhmann, B., Rainter, L., Schmaus, G. and Smeeding, T. (1988) Equivalence scales, wellbeing, inequality and poverty: Estimates across ten countries using the luxembourg income study database. Review of Income and Wealth, 34(2), 115-142.

ButricA, B.A., IAms, H.M. and SMith, K.E. (2006) The changing impact of social security on retirement income in the United States. In The Distributional Effects of Government Spending and Taxation, edited by Dimitri B. Papadimitriou, 112-132. Palgrave Macmillan UK, http://link.springer.com/chapter/10.1057/9780230378605_4.

ChIURI, M.C. and JAPPELLI, T. (2010) Do the elderly reduce housing equity? An international comparison. Journal of Population Economics 23(2), 643-63. http://dx.doi.org/10.1007/s00148$008-0217-4$.

Clark, W. (2005) What do seniors spend on housing?. Canadian Social Trends, 78, 2-7 (Statistics Canada Catalogue No. 11-008. Ottawa).

DeKKERS, G. and BeLloni, M. (2009) Microsimulation, pension adequacy and the dynamic model MIDAS: An introduction, projection AIM - deliverable 4.10.

DENTON, F.T., Finnie, R. and SPENCER, B.G. (2011) Income replacement in retirement: Longitudinal evidence from income tax records. Canadian Journal on Aging, 30(3), 1-17.

DENTON, F.T. and SPENCER, B.G. (2009) What is retirement? A review and assessment of alternative concepts and measures. Canadian Journal on Aging, 28(1), 63-76.

DeXTER, M. (1984) Replacement ratios: A major issue in employee pension systems. In National Committee on Public Employee Pension Systems, pp. 42-43. Washington, D.C.: National Committee on Public Employee Pension Systems, 1984.

Dodge, D.A., Laurin, A. and Busby, C. (2010) The piggy bank index: Matching Canadians' saving rates to their retirement dreams, C.D. Howe Institute. E-brief no. 95, Toronto, March 2010. Available at: http://www.cdhowe.org/pdf/ebrief_95.pdf 
Engen, E.M., Gale, W.G., and Uccello, C.E. (1999) The Adequacy of Household Saving. Brookings Papers on Economic Activity, 2, 65-187.

Fernandez-Villaverde, J. and Krueger, D. (2007) Consumption over the life cycle: Facts from consumer expenditure survey data. The Review of Economics and Statistics, 89(3), 552565.

Fidelity Research Institute (2007) The Fidelity Research Institute Retirement Index. Research Insights Brief; March.

FINNIE, R. (1999) Earnings mobility of Canadians, 1982-1992, Perspectives on Labour and Income. Statistics Canada Catalogue No. 75-001.XPE: 9-15. Statistics Canada.

FINNIE, R. and GRAY, D. (2011) Labour-force participation of older displaced workers in Canada: Should $i$ stay or should $i$ go?, IRPP Study No. 15. Institute for Research and Public Policy, Montreal, Quebec, February.

Flood, L., Jansson, F., Pettersson, T., Pettersson, T., Sundberg, O. and Westerberg, A. (2012) SESIM III - A Swedish dynamic micro simulation model.

GibSON, M.J., and HouSER, A. (2007) Valuing the Invaluable: A New Look at the Economic Value of Family Caregiving. Issue Brief (Public Policy Institute (American Association of Retired Persons)), no. IB82, 1-12.

Gourinchas, P.-O. and PARKer, J. (2002) Consumption over the life cycle. Econometrica, 70(1), $47-89$.

Government Accountability Office (GAO) (2001) Social security: Program's role in helping ensure income adequacy, Report No. GAO-02-62, Washington, D.C., November 2001.

GUAY, R. and JEAN, L.A. (2013) Long-term returns: A reality check for pension funds and retirement savings, C.D. Howe Institute Commentary No. 395 Pension Policy. December, Toronto.

Gustman, A. and SteinMeIER, T. (1998) Effects of pensions on savings: Analysis with data from the health and retirement study, Working Paper No. 6681, Cambridge, MA, August 1998.

HARDING, A. (2007) The Australian dynamic population and policy microsimulation model. In IMA Conference, Vienna, Austria.

Haveman, R., Holden, K., Wolfe, B., and Sherlund, S. (2006) Do newly retired workers in the United States have sufficient resources to maintain well-being? Economic Inquiry, 44(2), 249-64. doi:10.1093/ei/cbj023.

Holmer, M. (2009) Projecting Future U.S. Pension Benefits. Washington, D.C.: Policy Simulation Group.

Human Mortality Database (2013) University of California, Berkeley (USA), and Max Planck Institute for Demographic Research (Germany). Available at www.mortality.org or www.humanmortality.de (data downloaded on [06/01/2013]).

JAMES, E., VITTAS, D., and Song, X. (2001) Annuity markets around the world: Money's worth and risk intermediation, CERP Working Paper 16/01, Center for Research on Pensions and Welfare Policies, Moncalieri, Italy.

KeEFe, J., LÉGARÉ, J., CHARbonneAu, P. and DÉCARIE, Y. (2012) Intergenerational support to older Canadians by their adult children: Implications for the future. In The Family, the Market or the State? Intergenerational Support Under Pressure in Ageing Societies. International Studies in Population, Vol. 10 (ed. G. De Santis), pp. 141-158. Berlin: Springer Publisher. ISBN 97-94-007-4338.

KING, M. and Low, D. (2014) Measuring the 'World' real interest rate, NBER Working Paper 19887. Cambridge, MA.

KLevmarken, N.A. (1997) Behavioral Modeling in Micro Simulation Models. A Survey. Working Paper. Uppsala - Working Paper Series. http://econpapers.repec.org/paper/fthuppaal/199731.htm.

KOTLIKOFF, L. (2006) Is conventional financial planning good for your financial health, Boston University working paper 2006.

LARochelle-Cote, S., Myles, J. and Picot, G. (2008) Income security and stability during retirement in Canada, Analytical Studies Branch Research Paper Series. Cat. No 11F0019M, Ottawa.

LI, J. and O'Donoghue, C. (2013) A survey of dynamic microsimulation models: Uses, model structure and methodology. International Journal of Microsimulation, 6(2), 3-55.

Liu, H., Ostrovsky, Y., and Zhou, J. (2013) Statistics Canada, and Economic Analysis Division. Saving and Wealth: The Adequacy of Household Saving in Canada, http://www.deslibris.ca/ID/238491. 
MACDonAlD, B.-J., ANDREws, D. and BRown, R. (2010) The Canadian elder standard - pricing the cost of basic needs for the Canadian elderly. Canadian Journal on Aging/La Revue canadienne du vieillissement 29(1): 39-56.

MacDonald, B.-J., Moore, K., Chen, H. and Brown, R. (2011) Canadian national retirement risk index: employing statistics Canada's LifePaths to measure the financial security of future Canadian seniors. Journal of Canadian Public Policy, 37(1), 73-94.

MACDONALD, B.J. and OSBERG, L. (2014) Canadian retirement incomes: How much do financial market returns matter?. Canadian Public Policy, 40(4), 315-335.

MACDonalD, D. (2015) The feeling's not mutual. the high costs of Canada's mutual fund based retirement system. Canadian Centre for Policy Alternatives March 2015.

Mackenzie, G.A. (2010) The Decline of the Traditional Pension: A Comparative Study of Threats to Retirement Security. Cambridge, New York: Cambridge University Press.

MCGiLl, D.M. and WhARTON SCHOOL, EDS. (2010) Fundamentals of Private Pensions. New York: Oxford University Press.

MileVSKY, M.A. (2012) The 7 Most Important Equations for Your Retirement. Mississauga: John Wiley \& Sons,.

MilevsKy, M.A. and ShaO, L. (2010) Annuities and their derivatives: The recent Canadian experience. Pension Research Council Working Paper. Pension Research Council, University of Pennsylvania. Philadelphia. Available at: http://ssrn.com/abstract=1706893.

MiLEVSKY, M.A. and Young, V.R. (2007) Annuitization and asset allocation. Journal of Economic Dynamics and Control, 31(9), 3138-3177.

MiLLS, M.S. and Young, M.L. (2004) Facing the new facts of retirement income adequacy. Benefits Quarterly, 20(4), 40-47.

MitChell, O. and MoORE, J. (1998) Can americans afford to retire? New evidence on retirement saving adequacy. Journal of Risk and Insurance, 65(3), 371-400.

MODigliani, F. and BRUMBERG, R. (1954) Utility analysis and the consumption function: An interpretation of cross-section data. In Post-Keynesian Economics(ed. K. Kurihara), New Brunswick: Rutgers University Press. Pp 388-436.

Moore, J.F. and Mitchell, O.S. (2000) Projected retirement wealth and savings adequacy in the health and retirement study, In Forecasting Retirement Needs and Retirement Wealth (eds. S.M. Olivia, P. Brett Hammond and A.M. Rappaport), pp. 68-94. Philadelphia, PA: Pension Research Council and the University of Pennsylvania Press.

MoOre, K., RoBSON, W. and LAURIN, A. (2010) Canada's looming retirement challenge: Will future retirees be able to maintain their living standards upon retirement?, C.D. Howe Institute Commentary No. 317.

MorissetTe, R., ZHANG, X. and FrenetTe, M. (2007) Earnings losses of displaced workers: Canadian evidence from a large administrative database on firm closures and mass layoffs, Analytical Studies Branch Research Paper No. 291. Catalogue No. 11F0019MIE, Ottawa.

MORRISON, R.J. (2000) Assessing the quality of DYNACAN's synthetically-generated earnings histories. In Paper presented at the $6^{\text {th }}$ Nordic Conference on Microsimulation, June, 2000, Copenhagen, Denmark.

MUNNELL, A. (2005.May) Do people save enough for retirement? TIAA-CREF Trends and Issues.

Munnell, A., Golub-Sass, F. and WeBB, A. (2011) How much to save for a secure retirement, Center for Retirement Research at Boston College Issue Brief Number 11-13. August.

MunNell, A., Orlova, N. and WebB, A. (2013) How important is asset allocation to financial security in retirement? In The Market for Retirement Financial Advice (eds. O.S. Mitchell and K. Smetters), pp. 89-106. Oxford: Oxford University Press.

Munnell, A. and Soto, M. (2005) What Replacement Rates Do Households Actually Experience in Retirement? Boston: Center for Retirement Research.

Munnell, A., WebB, A. and Delorme, L. (2006) A New National Retirement Risk Index. Chestnut Hill, MA: Center for Retirement Research at Boston College.

Munnell, A., WeBB, A. and Golub-SASS, F. (2007a) What moves the national retirement risk index? A look back and an update, Center for Retirement Research at Boston College Issue Brief Number 7-1, January.

MunNell, A., WeBB, A. and Golub-SASs, F. (2007b) Is there really a retirement savings crisis? An NRRI analysis, Center for Retirement Research at Boston College Issue Brief Number 7-11, August. 
O'HARRA, J., SABelhaus, J.E. and Simpson, M. (2004) Overview of the congressional budget office long-term (CBOLT) policy simulation model. Congressional Budget Office.

OrganizATION FOR ECONOMIC CO-OPERATION AND DEVElopMent, OECD. (2009) Private Pensions and the Financial Crisis: How to Ensure Adequate Retirement Income from Defined Contribution Pension Plans? Working Party on Private Pensions.

Ostrovsky, Y. and Schellenberg, G. (2009) Pension coverage, retirement status, and earnings replacement rates among a cohort of Canadian seniors, Statistics Canada Analytical Studies Branch Research Paper Series, Ottawa, December 2009.

Palmer, B. (1988) The Impact of Tax Reform on Wage Replacement Ratios. Atlanta, GA: Center for Risk Management and Insurance Research at Georgia State University.

PALMER, B. (2008) 2008 GSUIAon RETIRE Project Report. Atlanta, GA: Center for Risk Management and Insurance Research at Georgia State University.

PICKARD, L. (2008) Informal care for older people provided by their adult children: Projections of supply and demand to 2041 in England, Report to the Strategy Unit (Cabinet Office) and the Department of Health, Discussion Paper 2515, London.

PICKARD, L. (2011) The supply of informal care in Europe, ENEPRI Research Report No. 94, CEPS, Brussels.

QUINN, J.P. (1999) Retirement patterns and bridge jobs in the 1990's, Employee Benefit Research Institute EBRI Issue Brief 206, Washington, DC.

ReInHart, C.M. and Rogoff, K. (2009) This Time is Different: Eight Centuries of Financial Folly. Princeton, NJ: Princeton University Press.

RuCKMAN, K. (2003) Expense ratios of North American mutual funds. Canadian Journal of Economics, 36(1), 192-223.

Russell, L.H., BRUCE, E.A., and CONAHAN, J. (2006) A methodology to determine economic security for elders. Washington, DC: Gerontology Institute, University of Massachusetts Boston, and Wider Opportunities for Women.

SCHIEBER, S.J. (2004) Retirement income adequacy: Good news or bad? Benefits Quarterly, 20(4), $27-39$.

SchOlZ, J. and SESHADRI, A. (2009) What replacement rates should households use?, Michigan Retirement Research Center Working Paper WP 2009-2014, Wisconsin.

SChwARTZ, D. (2010) Will a retirement boom start in 2011?. CBC News. December 31, 2010. Available at: http://www.cbc.ca/news/canada/story/2010/12/30/f-boomers-retire.html

SkINNER, J. (2007) Are you sure you're saving enough for retirement? Journal of Economic Perspectives, 21(3), 59-80.

SMITH, J. (2003) Trends and projections in income replacement during retirement. Journal of Labor Economics, 21(4), 755-781.

Social Security Administration (2008) The future of social security. Washington, DC: SSA (SSA Publication No. 05-10055, ICN 462560).

Social Security Administration (2012a) Social security programs throughout the world: Asia. Washington, DC: SSA, Office of Policy (SSA Publication No. 13-11802).

Social Security Administration (2012b) Social security programs throughout the world: Europe. Washington, DC: SSA, Office of Policy (SSA Publication No. 13-11801).

Social Security Administration (2013a) Social security programs throughout the world: Africa. Washington, DC: SSA, Office of Policy (SSA Publication No. 13-11803).

Social Security Administration (2013b) Social security programs throughout the world: Americas. Washington, DC: SSA, Office of Policy (SSA Publication No. 13-11804).

SPIELAUER, MARTIN with contributions from Chantal Hicks, Steve Gribble, Geoff Rowe, Xiaofen Lin, Kevin Moore, Laurie Plager, and Huan Nguyen (2013) The LifePaths Microsimulation Model: An Overview.

Statistics Canada Demography Division (2010) Population projections for Canada, provinces and territories 2009-2036, Cat. No. 91-520-X, Ottawa.

Statistics Canada (2006) The wealth of Canadians: An overview of the results of the survey of financial security 2005, Pension and Wealth Research Paper Series (Cat. No. 13F0026MIE-No. 001), Ottawa, 2006.

Statistics Canada (2011) Census. Living Arrangements of Young Adults Aged 20 to 29.2011 Census in Brief. Ottawa: Statistics Canada, 2012 (Cat. No. 98-312-X2011003). 
StEINBERG, A. and LuCAS, L. (2004) Shifting responsibility: The future of retirement adequacy in America. Benefits Quarterly: 15-26. Adapted from: Hewitt Associates. (2004) Total Retirement Income at Large Companies: The Real Deal.

Steuerle, C., Spiro, C. and CARASso, A. (2000) Do analysts use atypical workers to evaluate social security? In Straight Talk on Social Security and Retirement Policy, (19). Washington DC: The Urban Institute.

TD Economics (2010) Retirement income security reform: Rush prudently, don't run blindly. Special Report. Available at: http://www.td.com/economics/index.jsp.

The CANBerra Group (2001) Expert group on household income statistics: Final report and recommendations. Ottawa, Canada.

U.K. Government Department for Work and Pensions (DWP) (2013) Framework for the analysis of future pension incomes. Ref: ISBN 978-1-78153-799-2

VANDERHEI, J. (2004) Measuring retirement income adequacy, traditional replacement ratios, and results for workers at large companies. EBRI Notes, no. 9 (Employee Benefit Research Institute), September 2004. Washington DC.

VAnDerheI, J. (2006) Measuring Retirement Income Adequacy: Calculating Realistic Income Replacement Rates. Washington DC: Employee Benefit Research Institute.

VENTI, S.F. and WisE, D.A. (2001) Aging and housing equity. In Innovations for Financing Retirement. Pension Research Council Publications (eds. O.S. Mitchell, Z. Bodie, P. Brett Hammond and S. Zeldes) pp. 254-81. Philadelphia: University of Pennsylvania Press.

VENTI, S.F. and WISE, D.A. (2004) Aging and housing equity: Another look. In Perspectives on the Economics of Aging (ed. David A. Wise), pp. 127-75. Chicago: University of Chicago Press for NBER. http://dx.doi.org/10.7208/chicago/9780226903286.003.0004.

VinCENT, G.K. and VeLKOFF, V.A. (2012) US Census Bureau. "The next four decades the older population in the United States: 2010 to 2050. Population estimates and projections P25-1138." Washington, DC: US Dept. of Commerce, Economics and Statistics Administration, US Census Bureau; 2010.

Wolff, E.N. (2011) Pensions in the 2000s: The lost decade?, NBER Working Paper No. 16991. Cambridge, MA.

Wolfson, M. (2011) Projecting the adequacy of Canadians' retirement incomes: Current prospects and possible reform options, Institute for Research on Public Policy IRPP Study 17, Montreal.

\section{BONNIE-JEANNE MACDONALD (Corresponding author)}

School of Mathematical and Computational Sciences

University of Prince Edward Island

Halifax, Nova Scotia, Canada

E-Mail: Bonniejeanne_macdonald@hotmail.com

\section{LARS OSBERG}

McCulloch Professor

Department of Economics

Dalhousie University, Halifax,

Nova Scotia, Canada

E-Mail: lars.Osberg@Dal.Ca

KeVIN D. MoORE

Principal Researcher

Statistics Canada

Ottawa, Ontario, Canada

E-Mail: kevin.Moore@statcan.gc.ca 


\section{APPENDIX A}

Accurate measures of retirement income adequacy are probably more important today than ever before (in Canada and elsewhere), owing to

1. the low interest rate environment: Reinhart and Rogoff (2009), King and Low (2014), Guay and Jean (2013) all suggested a long-term low interest rate environment for Canada, and similar situations exist across industrialized countries. A continuing low interest rate environment reduces the accumulation of personal savings, heightens the cost of annuitization, and drives sponsors of underfunded DB pension plan sponsors to freeze and/or close pension plans (see MacDonald and Osberg, 2014 for an examination of the impact of a long-term low interest rate environment on the financial well-being of Canadian seniors),

2. high investment fees: In Canada, for example, the average Canadian mutual fund charged $2.1 \%$ in fees in 2014, while comparable average pension plan fees were $0.38 \%$ (MacDonald, 2015). Ruckman (2003) also found similarly high expense ratios for mutual funds, particularly in Canada,

3. longer life expectancies: From 1950 to 2009, the average life expectancy of a 65 yearold grew from 15.0 to 21.7 years for female Canadians and 13.3 to 18.6 years for male Canadians (Human Mortality Database, 2013),

4. rising divorce rates among seniors (with likely negative financial implications): Divorce rates more than doubled between 1990 and 2010 from $4.87 \%$ to $10.05 \%$ for Americans aged 50 and above (while U.S. population-wide divorce rates have declined) (Brown and Lin, 2012),

5. an aging population: A rapidly rising number of seniors accompanied by a slowly increasing labor force have raised concern regarding the capacity of governments to deliver promised benefits. For example, the ratio of Canadians aged 65 and over to those ages 20-64 in 2010 was $22 \%$ - growing to $41 \%$ by 2030 (Statistics Canada, 2010),

6. an increasing reliance on paid services for the potentially costly expenses associated with chronic health conditions: People aged 85 and above are most affected by chronic health conditions and their share of the population is rapidly growing (in 2010, there were three American seniors aged 85 and above for every hundred working-aged Americans — this is projected to grow to eight by 2050 (Vincent and Velkoff, 2012)). While the bulk of caregivers have historically been family and friends in most countries, this is expected to decline owing to fewer children, greater mobility of family members, greater workforce participation of women and changing expectations of care within families (among many, see Gibson and Houser, 2007; Pickhard, 2008, 2011; Keefe et al., 2012) and

7. less secure sources of retirement income: This uncertainty has arisen from

a. the shift among the design of employer pension plans from defined benefit (DB) (where the risk of the benefit payments is the responsibility of the employer) to defined contribution (DC) (where the risk lies with the individual) in many countries around the world (MacKenzie, 2010),

b. similar reforms of state pension systems in many countries from DB designs to DC individual accounts (countries with mandatory individual retirement schemes include Chile, Uruguay, Peru, Nicaragua, Mexico, Ecuador, Dominican Republic, Chile, Columbia, Costa Rica, Bolivia, Bulgaria, Croatia, Estonia, Latvia, Poland, 
Romania, Russia, San Marino, Slovak Republic, Sweden, Nigeria, Brunei, China, Kazakhstan, Kyrgyzstan and Uzbekistan (USA Social Security Administration, 2012a, 2012b, 2013a, 2013b)), as well as reductions in state pension benefits (such as increases in normal retirement ages, which removes guaranteed benefits during the delayed period - for example, the prominent proposal to delay U.S. Social Security benefits to ensure the solvency of the program),

c. the 2008 financial crisis and its immediate impact of reducing personal retirement savings (Wolff, 2011).

\section{APPENDIX B}

Rather than use a single target rate, some studies estimate a range of target gross replacement rates using survey data. This included Palmer $(1988,2008)$, which produced target gross replacement rates for workers classified by earnings level, region and marital status, using data from the U.S. Consumer Expenditure Survey. By matching workers and retirees with similar incomes in the survey year, its aim was to calculate, within each subgroup, the level of gross retirement income necessary to maintain a worker's available income (disposable income less net savings). Specifically, for each subgroup of workers, the goal was to use the survey data to solve for annual retirement gross income and taxes (retirement gross income and taxes were solved simultaneously since one affects the other) in

working gross income - taxes - workers net savings $=$ retirement gross income - retirement taxes - retirement net savings,

where

- workers net savings were calculated averages for the working members of the subgroup,

- retirement net savings were also calculated averages for retired members of the subgroup with similar income levels as the workers.

With the "retirement gross income" calculated, he estimated the target gross replacement rate for the subgroup as:

$=$ retirement gross income/working gross income .

Palmer further produced a second set of replacement rate targets, which incorporated the impact of period-specific expenses that do not exist in both pre- and post-retirement, such as those associated with employment and senior aging.

The methodology underlying Palmer's empirical measure of target gross replacement rates was first developed in Dexter (1984). For an illustration and additional explanation of the conceptual model of building target gross replacement rates, see McGill et al. (2010, Chap. 7). 
Mitchell and Moore (2000) and Munnell et al. (2006) took conceptually similar approaches to estimate target gross replacement rates, but they further evaluated whether current workers (future retirees) appear to be on track to achieving them.

\section{APPENDIX C: METHODOLOGICAL ISSUES OF THE CONVENTIONAL EARNINGS REPLACEMENT RATE}

This section discusses the methodological issues associated with the conventional earnings replacement rate listed in Section 2, and gives some examples of the various approaches employed by analysts.

\section{C.1. Household-level differences in consumption due to family size}

The conventionally measured earnings replacement rate is done at the individual level. Economists have long recognized, however, that most individuals live in households and share consumption with others, implying that household or family income should be used when determining living standards. In the context of retirement income adequacy, this also implies that parents need less income in retirement to maintain their pre-retirement standard of living, relative to childless individuals with similar pre-retirement income, since a large fraction of a parent's pre-retirement budget is devoted to supporting children.

A widely accepted method of accounting for family size and economies of scale is to assign each person in the household an "equivalent income". The Luxembourg Income Study (LIS) equivalence scale sets this amount of income equal to total household income divided by the square root of household size, and is the methodology employed in this study.

The replacement rate literature has been diverse in terms of unit of analysis. Some replacement rate studies have used individuals (VanDerhei, 2006; Ostrovsky and Schellenberg, 2009), while others include spouses (Mitchell and Moore, 1998; Munnell et al., 2006). Some studies have used individuals as the unit of analysis, but calculate per-capita income at the level of couples (Butrica et al., 2006) (for example, if the consumption of one spouse is $\$ 100,000$ and the other zero, each spouse would be assumed to have consumed $\$ 50,000)$. Studies that use longitudinal data have to contend with the fact that marital status changes through time. For example, it is not obvious whether a man who marries in the year leading up to his retirement should be considered married or single for the purposes of computing his replacement rate. Smith (2003) discussed these issues (including transitions to widowhood) between pre-retirement and post-retirement, and adjusted replacement rates accordingly by using an equivalency scale.

While analysts often incorporate marital status, children are routinely not considered (for discussion, see Scholz and Seshadri, 2009: 3). Examples of replacement rate studies that construct replacement rate measures where pre-retirement consumption is explicitly reduced to reflect the costs of supporting dependent children include Larochelle-Cote et al. (2008), Scholz and Seshardri (2009), Moore et al. (2010) and MacDonald et al. (2011). 


\section{C.2. Components of income}

Early literature tended to restrict the included sources to those found in income data (Boskin and Shoven, 1987; Palmer, 1988), and this approach continues in studies that rely exclusively on this data source (Smith, 2003; Larochelle-Cote et al., 2008; Ostrovsky and Schellenberg, 2009). Although some sources of income are adequately captured in traditional income data or administrative data, others are not. For example, the drawdown (or dissavings) of nonregistered assets, which includes non-tax-sheltered savings held in bank accounts, bonds, mutual funds, stock markets and certain annuities, is not captured in traditional income data sources; only the annual yield on such capital is "income". For savings in the form of home ownership, neither the imputed rent, mortgage payments, nor the consumption represented by its drawdown are visible in such data.

Instead of using earnings to solely determine the replacement rate denominator, Munnell and Soto (2005) and Munnell et al. (2006) included pre-retirement investment income in the replacement rate denominator. Smith (2003), LaRochelle-Cote et al. (2008) and MacDonald et al. (2011) incorporated investment income as well as government transfers (such as social assistance, EI and child benefits).

"Imputed rent" has been considered by Munnell and Soto, 2005, Munnell et al., 2006, Moore et al., 2010, MacDonald et al., 2011 and Wolfson, 2011. Imputed rent can be regarded as a form of investment income - the return from savings that are held in the form of real property, rather than in financial assets. Including imputed rent in the replacement rate recognizes that homeowners who have some equity in their homes are enjoying a flow of services that is an important source of household consumption (Brown et al., 2010). The importance of imputed rent continues to apply in retirement, particularly given that the cost of shelter is the largest expenditure from among a healthy senior's basic costs of living (MacDonald et al., 2010) and that seniors are more likely to own their home than any other age group (in Canada, see Statistics Canada, 2006).

With regards to pre-retirement savings, Palmer (1988) developed target gross replacement rates using a measure that reasonably captured most forms of savings, but appeared to omit the savings represented by paying down one's mortgage. The target gross replacement rates developed by Mitchell and Moore (1998) and Brady (2010), on the other hand, included the reduction of mortgage principal in pre-retirement savings. Using micro-simulation modeling, Moore et al. (2010) and Wolfson (2011) incorporated pre-retirement savings in the form of employer-sponsored pension plans, registered retirement savings plans and paying down mortgages. MacDonald et al. (2011) took a somewhat more comprehensive approach by also measuring non-registered wealth and debt accumulation (including financial assets/debts, real-estate investments and equity in businesses owned).

Personal wealth includes equity in an owner-occupied home, which therefore could be seen as a component of retirement savings. Many argue that homes are a special case, however, and that an assessment of the replacement adequacy of the retirement income system should not assume that retirees sell their homes or otherwise deplete their home equity. Excluding this asset class, which for most Canadians is the single largest net asset (Statistics Canada, 2006), clearly distorts important differences in financial security between homeowners and renters, and between homeowners with very different amounts of home equity. Gustman and Steinmeier (1998), Moore and Mitchell (2000), Munnell et al. (2006) and Munnell et al. (2007a, 2007b) explicitly included the drawdown of all housing wealth in addition to financial assets. Moore et al. (2010) included both imputed rent and the drawdown of registered assets, and also explored the impact of drawing down different proportions of home equity. Engen et al. (1999) included half of home equity (this half-way point was supported by Munnell, 
2005). MacDonald et al. (2011) included imputed rent and the drawdown of registered and non-registered wealth, but did not include home equity, which was assumed to not be consumed in retirement.

Replacement rate studies are divided on the issue of employment earnings as a component of retirement income. In most of the literature, earnings are expressly excluded on conceptual grounds that the purpose of a "replacement rate" is to evaluate the extent that employment earnings have been replaced after retirement (where retirement is the cessation of employment) (Mitchell and Moore, 1998; Munnell et al., 2006; Biggs and Springstead, 2008; Moore et al., 2010; MacDonald et al., 2011). In other studies, earnings are either purposely included in the numerator, or are included in a broader "total income" variable (Boskin and Shoven, 1987; Smith, 2003; Larochelle-Cote et al., 2008).

Income taxes should be subtracted from gross pre- and post-retirement income. This is done directly for each individual if individualized targets are being employed (such as in MacDonald et al., 2011). Otherwise, when averages are used to determine target gross replacement rates (such as explained in Appendix B), differentials in income taxes pre- and post-retirement are incorporated into the target gross replacement rates.

\section{C.3. The volatility of earnings and retirement income}

One of the most central methodological issues in designing a replacement rate measure is the choice of measurement period for the denominator. The measurement period used to calculate pre-retirement earnings can have an enormous impact on the resulting replacement rate, leading to quite different conclusions about replacement adequacy.

The "replacement rate" goal is the preservation of pre-retirement living standards, but this leads to the question: pre-retirement living standards measured over what period? Much of the consumption literature finds that the average shape of consumption over an individual's life has a distinct "hump" shape (Gourinchas and Parker, 2002; Fernandez-Villaverde and Krueger, 2007). On average, annual consumption early in an individual's career closely tracks earnings and typically rises at a relatively rapid pace. After an individual reaches their "prime" working years, however, annual consumption increases much more gradually or even levels off completely. Consumption tends to peak in late middle-age, and starts declining gradually thereafter, even as annual earnings remain flat or continue to increase.

The most important complications arise, however, because replacement rate denominators are typically calculated using gross earnings and not income for consumption expenditure (see Equation (1)). Annual earnings have considerable year-over-year variation (Morrison, 2000), which creates complex and diverse earnings histories across individuals. Many individuals exhibit tremendous "earnings mobility" ${ }^{15}$ and consequently occupy quite different rankings in the distribution of earnings over the course of their careers (Finnie, 1999; Beach and Finnie, 2004). Overall, it cannot be assumed that a narrow measurement period is "representative" of earnings since it will reflect different things for different individuals.

Further, much of the theoretical literature relating to life-cycle income and consumption suggests that the relationship between an individual's standard of living and his/her earnings measured over any particular short-term period may be quite weak (a theory that began with Modigliani and Brumberg, 1954). Diminishing marginal utility implies that individuals prefer a relatively consistent standard of living, so they smooth their consumption over long time horizons, such as their entire lifetimes, rather than making current consumption decisions based primarily on current income (ibid).

In the applied replacement rate literature, there is tremendous diversity in the measurement periods used to calculate the pre-retirement denominator. As we discuss below, this 
diversity applies both to the part of the life-course chosen, and the number of years averaged in the calculation.

Some studies use only one year of data. For example, Palmer's work $(1988,2008)$ relied on a single cross-sectional year of data with individuals between ages 50 and 64, whom he averaged across to produce the denominator of his replacement rate measure. Mitchell and Moore (1998) essentially used final earnings, but the denominator was calculated deterministically by taking a single year of data (an individual's earnings in 1992) and assuming constant real wage growth until retirement. Munnell et al. (2006) similarly began with data on a household's pre-retirement income in a single year, 2003, and projected it forward to retirement age according to an average earnings profile. Using only one year of data, and projecting any remaining years from this one observation in a highly stylized manner, ignores the substantial variation in many individuals' earnings.

Brady (2010) calculated average career earnings from ages 30 to 67 , but relied on a handful of illustrative individuals with stylized earnings histories.

Using longitudinal earnings data, Smith (2003), LaRochelle-Cote et al. (2008) and Ostrovsky and Schellenberg (2009) all averaged the earnings of each sampled individual from ages 54 to 56, which were characterized as "peak" and "permanent" earnings. Given the substantial variability in employment and earnings across many individuals' life-courses, average earnings for this age range will represent neither peak nor permanent earnings for a significant number of individuals (Finnie, 1999; Morissette et al., 2007; Finnie and Gray, 2011).

Munnell and Soto (2005) used approximately forty years of longitudinal micro-data on individual earnings to calculate both career-average and final average (best 5 of final 10) measures for the denominator. Boskin and Shoven (1987) similarly used 23 years of longitudinal earnings micro-data to calculate career average and final average (best 3 of final 10) measures. The impact of the chosen measurement period had a substantial impact in both studies.

As noted in Section 3, studies that use large-scale, dynamic micro-simulation models have nearly complete flexibility in choosing the pre-retirement measurement period in the denominator - such as in Butrica et al. (2006), Moore et al. (2010), MacDonald et al. (2011) and Biggs and Springstead (2008).

Relative to earnings, retirement income sources tend to be much smoother, although there are some exceptions, including marital transitions during the retirement years, especially to widowhood, which can affect retirement income stability. In addition, pension income that is not indexed to inflation, such as some employer pensions or most private annuities, can fall substantially in real value over the course of an individual's retirement. This suggests that a broad "retirement average" measurement period should be preferred for post-retirement income or consumption, rather than a narrow measurement period (such as the first year after retirement).

Most of the literature has used a single, cross-sectional snapshot of post-retirement income (Palmer, 1988; Smith, 2003; Ostrovsky and Schellenberg, 2009). Conventionally, replacement rate studies have tended to look specifically at income in the first year of retirement (GAO, 2001).

Some researchers have applied adjustments to contend with the short post-retirement measurement period of one year in conventional replacement rates. For example, assuming a one-year measurement period in retirement, Steinberg and Lucas (2004) suggested increasing conventional targeted replacement rates by 10 to 15 percentage points to compensate for the lack of inflation indexing in many retirement benefits (the lower range would be for lowincome seniors, who rely largely on inflation-indexed Social Security benefits). Alford et al. (2004) made similar adjustments. 
Some studies have taken snapshots of replacement rates at several different ages postretirement, including Biggs and Springstead (2008). Larochelle-Cote et al. (2008) stands out in this regard, as it used longitudinal data to follow individuals and couples through their retirement years, from ages 55 to 80, with a particular focus on the evolution of their replacement rates over time and the stability of their retirement income.

\section{C.4. Pre-and post-retirement financial risks}

Workers and seniors face different risks. The major income source risk for workers are labor market risks such as unemployment. For seniors, it is generally investment rate risk, inflation risk, generating an expensive medical condition and living "too long" (that is, outliving their financial resources). Unlike workers, seniors have fewer opportunities to react to these risks - for example, it is usually less feasible to return to the labor market if investments perform poorly. Consequently, post-retirement risk is an important area of study. ${ }^{16}$

Typically, replacement rate measures have not explicitly accounted for important risks of retirement that can affect a senior's financial well-being - namely, the risk of accelerating inflation, the death of a spouse, divorce, insurer default, low investment returns, annuitization rates, longevity, developing a health condition that generates significant out-of-pocket expenditures, unanticipated expenses (such as replacing a roof and other home repairs), increase in public taxes, DB pension plan default and changes in retirement benefits by government and private plan sponsors (such as reductions in pension income, retiree medical benefits, pension cost-of-living adjustments and other plan design features — see Mills and Young, 2004 for a discussion of such changes over the past decade in U.S. employer pension plans).

Schieber (2004) wrote that "singular rules of thumb for replacement rates are naive and that estimates should take into account the unforeseen risks that individuals face" (abstract). How to incorporate these risks is unclear, however, particularly for conventional replacement rate measures where the typical post-retirement measurement period is the first year of retirement. Choosing average or median costs is problematic - for instance, an individual either has a major health condition or does not, and therefore incorporating the median cost of any particular illness in a replacement adequacy measure will be insufficient for half of the population and cause the other half to unduly reduce their pre-retirement standard of living in order to save for an event that does not occur. The VanDerhei (2006) study offered one possible approach - he explicitly modeled the risk of catastrophic medical expenses, low investment returns and longevity, and used micro-simulation to simulate the distribution of possible future outcomes in order to demonstrate the uncertain financial impact of each contingency on retirement income adequacy targets. VanDerhei explained that the individual could choose the target that most appropriately fit his or her level of risk aversion (for example, a highly risk-averse person might choose the target replacement rate providing a $90 \%$ likelihood of maintaining a specified standard of living in retirement).

Holmer (2009) provided another approach. Based on five hundred different macroeconomic projection scenarios, he calculated replacement rates from expected risk-adjusted retirement income flows (rather than expected average retirement income flows). For the 1990 American birth cohort, as an example of the results, he found that "the risk-adjusted pension benefit is substantially smaller than the risk-adjusted social security benefit, even though the average (non-risk-adjusted) pension benefit is roughly the same as the average social security benefit" (abstract). 


\section{C.5. Purchasing power differences of income before and after retirement}

How do replacement rates account for the fact that the denominator will be measured at a different time than the numerator (the former being before retirement and the latter being after retirement)? Most studies express the numerator and denominator in constant dollars using the consumer price index. An alternative method is to use wage indexation, which is the approach traditionally taken by the U.S. Social Security Administration in its calculation of social security replacement rates, and was also used by Butrica et al. (2006) and Wolfson (2011). Using a consumer price index compares an individual's retirement income to the absolute level of pre-retirement consumption he/she actually experienced, while using a wage index also incorporates a comparison to the consumption of currently working generations. For most purposes, replacement rates are used to evaluate whether retirees' own consumption falls after retirement, rather than to make intergenerational comparisons and, for this reason, price indexation is most commonly used.

\section{C.6. Individual preferences for risk aversion, leisure and bequest}

As Section 2 noted, an alternative conception of retirement income adequacy employs a utilitarian framework (such as in Engen et al., 1999; Scholz and Seshadri, 2009; Liu et al.; 2013). Although a utilitarian framework suffers from complexity in modeling true individual preferences, it is considered an ideal framework in the study of living standards as it has the capacity to "(1) reflect differences in leisure as well as all forms of potential consumption, including home production and publicly provided goods; ... (2) account (for) differences in constraints faced both by people living in the same country, and differences in constraints faced by people in different countries; ... (and) (3) account for differences in the ability to smooth income across periods" (Canberra Group, 2001: 2). Despite these advantages of the utilitarian framework, it is commonly agreed to be too complex to implement for most users of replacement rates.

\section{C.7. Changes in expenses/spending over the life course}

Replacement rates are concerned only with the replacement of pre-retirement consumption expenditure in post-retirement. There can be, however, period-specific consumption that does not need to be replaced in post-retirement and/or new post-retirement consumption that does not occur in pre-retirement. Consequently, an individual with an unchanging standard of living before and after retirement could in fact have different consumption levels owing to the effects of aging and the cessation of employment.

For example, expenses associated with employment generally cease after retirement, such as professional development fees, commuting to work costs and the expense of special clothing (Figure 1 incorporates this commonly acknowledged changing expense, although we do not model it in our analysis). Further, retirees are better able to "stretch their dollar" owing to senior discounts and greater time for home production, consequently a dollar of retirement income could be more valuable than a dollar while working - for instance, it has been observed in both Canada (Brzozowski and Lu, 2010) and the U.S. (Aguiar and Hurst, 2005) that retirees spend less on food but still maintain the same quality of diet owing to more efficient shopping and cooking more at home. Similarly, Brancati et al. (2015) and Milevsky (2012) found that real consumption declines with age after retirement. On the other hand, medical expenses are likely to rise with age, particularly those associated with a chronic health condition. 
Should period-specific consumption be incorporated in the study of retirement income adequacy? The cost of medical care is likely the most material since it is both a necessary cost and a potentially significant one depending on the public/private nature of the state health care system and the coverage afforded by the retiree's employer. This is particularly true at advanced ages when the likelihood of suffering from acute and chronic health conditions is much higher. For instance, for those who need it, the expense of home care is a great concern since the onset of a chronic illness can be sudden and beyond the individual's control, and the out-of-pocket cost can become quite substantial in both the U.S. (Russells et al., 2006) and Canada (MacDonald et al., 2010).

Analysts have the option to either integrate period-specific consumption (all components or those that are deemed most important) or to treat them as a topic outside of a replacement rate framework. For instance, new and significant retirement expenses (notably medical) could be investigated separately such as through a precautionary saving, or insurance type analysis. Alternatively, period-specific consumption could be built into a replacement rate analysis by being subtracted from the income for consumption expenditure from Figure 1.

In past replacement rate literature, the topic of period-specific consumption has been either not addressed, or done so very loosely in a wide variety of manners. For instance, Dexter (1984) included all components as a one-off net change in consumption requirements at retirement when developing target replacement rates. Building on Dexter (1984), Palmer (1988) defined this variable as:

\section{Work-related expenses + Net Change in Age-Sensitive Expenditures.}

Palmer then developed two sets of target replacement rates - those with and without ageand work-related changes in consumption. McGill et al. (2010) took a similar approach, but modeled these two categories of expenses using regression analysis. As explained in Appendix C.4, however, using average or median change in necessary expenditures can be problematic, particularly when the expense is associated with an unknown post-retirement risk.

Steinberg and Lucas (2004), Alford et al. (2004) and Schieber (2004) used a conceptually similar approach as Palmer (1988) and subtracted net retiree medical costs from postretirement income in the conventional gross employment earnings replacement rate calculation. VanDerhei (2006) integrated the cost of medical expenses after retirement into the replacement rate analysis using a different approach. He explicitly modeled medical expenses over the lifetime of the retiree to assess the adequacy of conventional gross employment earnings replacement rates. As noted above, however, most replacement rate studies do not address period-specific consumption.

\section{APPENDIX D: LIFEPATHS -TOOL OF ANALYSIS}

Statistics Canada's LifePaths is one of the world's largest dynamic micro-simulation models of society. By integrating many data sets within Statistics Canada, LifePaths builds entire synthetic populations by simulating the detailed life-courses of virtual Canadians case by case. These virtual individuals attend school, make educational choices, leave home, form families, migrate, become parents, divorce and remarry, lose and find jobs, earn money, acquire homes, save, pay taxes, contribute to pension schemes, receive benefits and pensions, become 


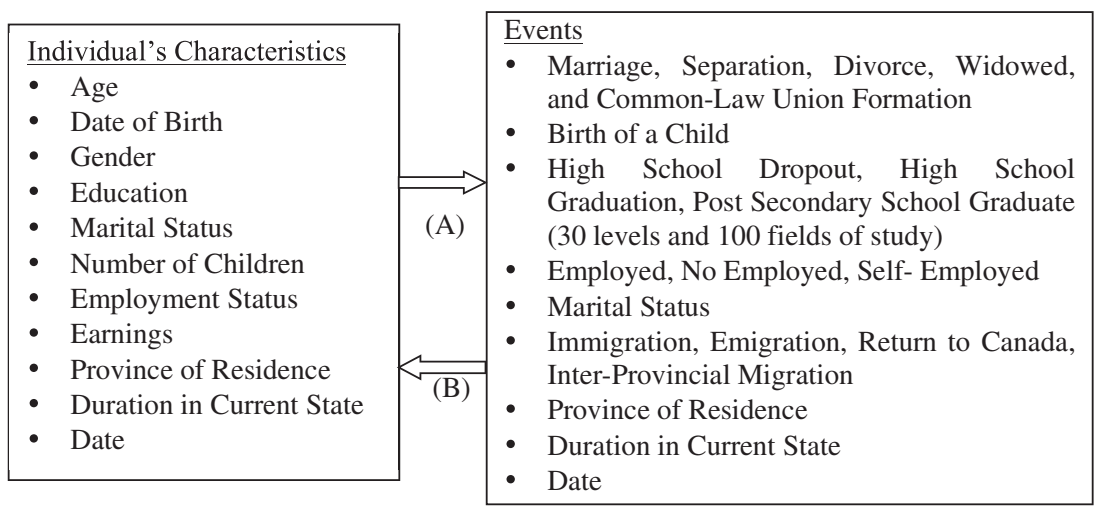

FIGURE D.1: Illustration of LifePaths' simulation of a Canadian life-course. Source: MacDonald et al. (2010, Fig. 1) .

disabled, and eventually die. LifePaths simulations aggregate to historical data over the past half-century and allow for detailed projections into the future (projections that incorporate the realistic complexity and diversity both across individuals and within life-courses).

Figure (4) represents the evolution of a simulated life in LifePaths. This is a simplified flow chart for illustration purposes, and is not intended to convey the true complexity of LifePaths. We list only some of the components of LifePaths - marital status, fertility, education, employment, and migration. For each simulated life, LifePaths tracks the individual's relevant characteristics, such as those listed in the first box. These characteristics enter as explanatory variables to determine the times until the occurrence of each possible event (arrow A). The event with the shortest wait time "wins" and, once it occurs, the individual's characteristics are updated (arrow B). These characteristics then enter again as explanatory variables to determine the next event (arrow A). This continues until death, thus creating a complete life course with all of the necessary details for millions of simulated Canadians. (MacDonald et al., 2010: 76).

LifePaths integrates a tremendous amount of micro-data and aggregate data in its behavioral equations and other modeling elements to faithfully reproduce the historical socioeconomic experience of Canadians. The model simulates detailed and diverse individual life courses using a variety of statistical methods, with particular emphasis on statistical eventhistory equations estimated from a broad array of data sources. Micro-data with a longitudinal component are taken advantage of wherever possible. Key data sources that are used to develop the model are historical demographic estimates of population, immigration, emigration, fertility, mortality, census micro-data from 1971 to 2006, longitudinal Labour Force Survey (LFS) data from 1976 to 2005, Family History surveys from 1984 to 2001, administrative data on post-secondary education, the 1999 and 2005 Survey of Financial Security (SFS), and longitudinal and/or cross-sectional taxation data from 1980 to 2011. Many other data sources have also been used to a lesser degree. Other than the exceptions noted below, the scenario underlying the main results of this report is the "default" LifePaths scenario, which generally assumes the continuation of recently observed socio-economic outcomes.

LifePaths is publicly available and has been under development for over two decades. An overview of LifePaths can be found at Statistics Canada Modelling Division (Spielauer, 
2013), which is publicly available for the interested reader and can be found on the Statistics Canada website: http://www.statcan.gc.ca/microsimulation/lifepaths/lifepaths-eng.htm.

Li and O'Donoghue (2013) provides an international context for LifePaths through comparison with other dynamic micro-simulation models. LifePaths is particularly notable in its use of continuous rather than discrete time, and its use of an open, rather than closed, population methodology.

We carried out our analysis by building on LifePaths Model version 5.1.4.4. The assumptions and calculations underlying the simulation results were prepared by the authors and the responsibility for the use and interpretation of these data is entirely that of the authors. In addition to working code that collects and calculates our measures of interest, we developed and integrated into LifePaths an improved annuity price calculator that realistically incorporates the relevant personal and financial market inputs akin to actual Canadian annuity providers. We also updated the financial market model up to the end of 2012. 